\title{
Development of a Screened Cathode Gas Flow Proportional Counter for In Situ Field Determination of Alpha Contamination in Soil
}

\section{by \\ Stephanie P. Bush}

RECEIVED

JUN 121997

OSTI

A Thesis Submitted in Partial Fulfillment

of the Requirements for the Degree of Master of Science

(Rackham School of Graduate Studies) at the University of Michigan.

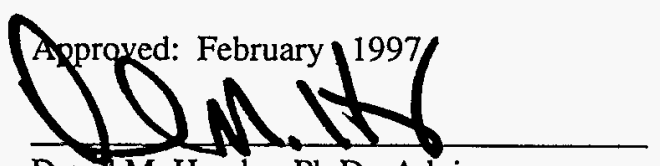

David M. Hamby, Ph.D., Advisor

Assistant Professor of

Radiological Health

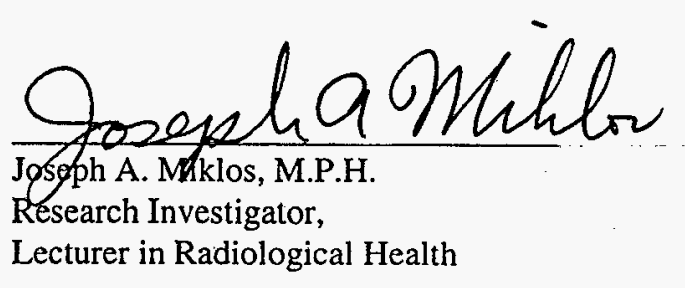

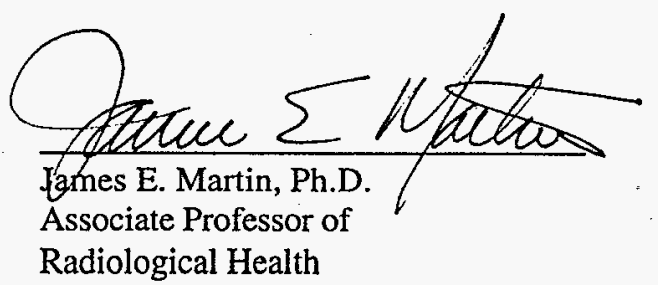

Radiological Health 
Masters Thesis

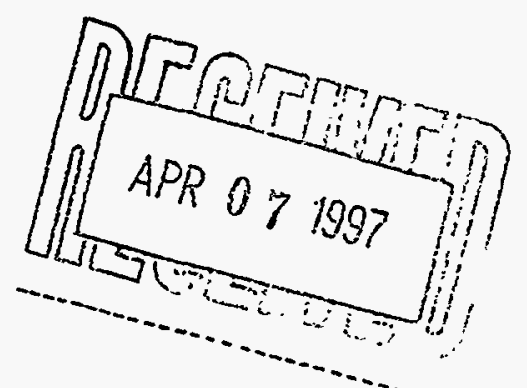

Development of a Screened Cathode Gas Flow Proportional Counter for In Situ Field Determination of Alpha Contamination in Soil

by

Stephanie P. Bush

A Thesis Submitted in Partial Fulfillment

of the Requirements for the Degree of Master of Science

(Rackham School of Graduate Studies) at the University of Michigan.

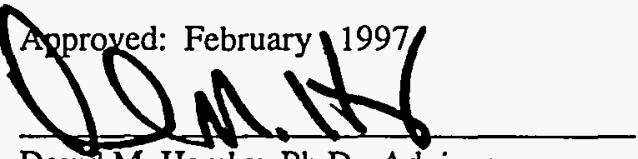

David M. Hamby, Ph.D., Advisor

Assistant Professor of

Radiological Health

Dosesha Milo

Joseph A. Milos, M.P.H.

Research Investigator,

Lecturer in Radiological Health

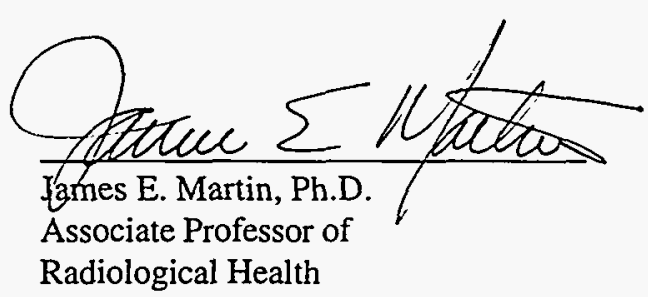

Radiological Health

MASTER

DISTRIBUTION OF THIS DOCUMENT IS UNLIMITED 


\section{DISCLAIMER}

This report was prepared as an account of work sponsored by an agency of the United States Government. Neither the United States Government nor any agency thereof, nor any of their emplovees. make any warranty, express or implied, or assumes any legal liability or responsibility for the accuracy, completeness, or usefulness of any information, apparatus, product, or process disclosed, or represents that its use would not infringe privately owned rights. Reference herein to any specific commercial product, process. or service by trade name, trademark, manufacturer, or otherwise does not necessarily constitute or imply its endorsement, recommendation, or favoring by the United States Government or any agency thereof. The views and opinions of authors expressed herein do not necessarily state or reflect those of the United States Government or any agency thereof. 


$$
=
$$




\begin{abstract}
This study resulted in the design, construction and testing of a gas flow proportional counter for in-situ determination of soil contamination. The uniqueness of this detector is the screened material used for the cathode. A Pu-239 source of $0.006 \mu \mathrm{Ci}$ was mounted to the outside of the cathode to simulate radioactive soil. The detector probe was placed into a laboratory mock-up and tested to determine operating voltage, efficiency and energy resolution.
\end{abstract}

Two gas flow proportional counters were built and tested. The detectors are cylindrical, each with a radius of $1.905 \mathrm{~cm}$, having an anode wire with a radius of $0.0038 \mathrm{~cm}$. The length of the smaller detector's anode was $2.54 \mathrm{~cm}$, and the length of the larger detector's anode was $7.64 \mathrm{~cm}$. Therefore, the active volumes were $28.96 \mathrm{~cm}^{3}$ and $87.10 \mathrm{~cm}^{3}$, respectively, for the small and large detector.

An operating voltage of 1975 volts was determined to be sufficient for both detectors. The average efficiency was $2.59 \pm 0.12 \%$ and $76.71 \pm 10.81 \%$ for the small volume and large volume detectors, respectively. The average energy resolution for the low-energy peak of the small detector was $4.24 \pm 1.28 \%$ and for the large-energy peak was $1.37 \pm$ $0.66 \%$. The large detectors' energy resolution was $17.75 \pm 3.74 \%$. The smaller detector, with better energy resolution, exhibited a bi-modal spectrum, whereas the larger detector's spectrum centered around a single broad peak. 


\section{Dedication}

Dedicated to the ancestors, your struggles were not in vain.

$* * * * * * * * * * * * * * * * * * * * * * * * * * * *$

\section{Acknowledgments}

To Michael,

who convinced me that I would get into Michigan and SUCCEED! You were right.

To my mother Alice, who gave me all she could and could not.

To Dr. Hamby and Dr. Martin for the opportunity to succeed.

Lastly, to ORISE, your monetary support was a GODSEND, I could not have made it without you.

The research was performed, in part, under appointment to the Applied Health Physics Fellowship program administered by Oak Ridge Institute for Science and Education for the U.S. Department of Energy. 


\section{TABLE OF CONTENTS}

Abstract ii

Dedication and Acknowledgments iii

Table of Contents iv

List of Tables vi

List of Figures vii

List of Appendices $\quad$ ix

Chapter 1

1. Introduction

1.1 Problem Statement

1.2 Objectives

2. Background

2.1. Recent Applications of Soil Monitoring

2.2 Introduction to Detectors

2.3 Introduction of Proportional Counters

2.4 Proportional Counter Theory

2.4.1 Gas Multiplication, Fill Gases and Choice of Geometry

2.4.2 Detector Efficiency

2.4.3 Energy Resolution and Statistical Considerations

3. Theoretical Design Concept and Detector Construction 13

3.1 Introduction

3.2 Design of the Detector

3.2.1 Choice of Geometry

3.2.2 Application of Multiplication Factor

3.3 Construction and Physical Characteristics of the Detector

3.3.1 Materials Used

3.3.2 Building the Detector

3.3.3 Fill Gas Application

3.3.4 Pulse Shaping and Processing 
4. Experimental Methods

4.1 Introduction

4.2 Establishing Operating Voltage

4.3 Measuring Background, Efficiency and Energy Resolution

4.4 Minimum Detectable Activity

5. Voltage, Efficiency and Energy Resolution Results

5.1 Introduction

5.1.1. Characteristics of the Pu-239 Source

5.1.2 Background measurements of the detector

5.2 Counting Curves

5.2.1 Small Detector with Source Bored in Soil

5.2.2 Small Detector with Source Attached to Cathode

5.2.3 Counting Curve for Large Detector

5.3 Detector Efficiency

5.4 Energy Resolution

5.4.1 Energy Resolution for the Small Detector

5.4.2 Energy Resolution for the Large Detector

5.5 Statistics of Counting Data

5.6 Minimum Detectable Activity

6. Discussion and Conclusion

6.1 Introduction

6.2 Discussion of Results

6.2.1 Problems Encountered with Design and Construction

6.2.2 Discussion of Curves, Efficiency and Energy Resolution

6.3 Conclusions

6.4 Future Studies

7. Contributions to Health Physics and Longterm Significance 46

8. References

9. Appendix 


\section{LIST OF TABLES}

Table 1. Factors Affecting Design Process

Table 2. Theoretical Data in Gas Multiplication Process

Table 3. List of Prominent Decay Energies of Pu-239

Table 4. Counting Curve Data for the Pu-239 Source Bored in Hole

Table 5. Counting Curve Data for the Small Detector with Source Taped to Cathode

Table 6. Counting Curve Data for the Large Detector

Table 7. Efficiency Data

Table 8. Energy Resolution Data for Small Detector

Table 9. Energy Resolution Data for Large Detector

Table 10. Mean, Standard Deviation, Variances and Chi-Square of Data

Table 11. Comparison to Semiconductor Detector Data 


\section{LIST OF FIGURES}

Figure 1. A Conventional Proportional Counter

Figure 2. Multiplication Factor versus Applied Voltage

Figure 3. Screened Cathode Gas Flow Proportional Counter

Figure 4. Electronic Setup

Figure 5. Complete Experimental Setup

Figure 6. Background Counts without Pu-239

Figure 7. Counting Curve for the Small Detector

Figure 8. Counting Curve of Source Placed in Bored Hole

Figure 9. Counting Curve for the Large Detector

Figure 10. Spectrum of Pu-239 at 1900 Volts

Figure 11. Spectrum of Pu-239 at 1975 Volts 


\section{LIST OF APPENDICES}

Appendix A Gas Multiplication Process Data

Appendix B Decay Scheme of Pu-239

Appendix C Statistics and Background Data

Appendix D Counting Curve Data

Appendix E Efficiency and Energy Resolution Data

Appendix F Semiconductor Data 


\section{CHAPTER 1 \\ INTRODUCTION}

\subsection{Problem Statement}

While the Cold War is over, its legacy remains. Its legacy is the entire nuclear weapons complex that has generated waste, pollution and radioactive contamination. Individual facilities within the complex must be managed and restored. The Department of Energy is actively pursuing new technologies that will aid in the cleanup process and there are a number of challenges to be met. For example, at the Hanford Site in Washington State, tritium has been detected in the ground water, and high-level waste has leaked from storage tanks. At Fernald, Ohio, several hundred tons of uranium were emitted into the atmosphere, and drinking-water wells were contaminated with uranium. Traces of plutonium have been found in the soil and sediments around the Rocky Flats site in Colorado. These and other examples are well documented in the United States Department of Energy's booklet, Closing the Circle on the Splitting of the Atom.

The Cold War legacy is not confined to the United States borders. About 98 percent of the nuclear weapons production occurred between the United States and the former Soviet Union. The former Soviet Union has poured large quantities of high-level waste into rivers and lakes or injected it deep underground. These widespread discharges of radioactive contamination have left the former Soviet Union with sites that must be decontaminated or controlled.

Environmental restoration of the United States facilities and their adjacent waste sites involves several processes. Overall, there is detailed study of the site, research and selection of the best clean up technique, and finally site restoration. Detailed study of the site or site characterization is one of the most extensive processes. In particular to radioactive waste sites, this process involves sampling of environmental media for 
radioactive contaminants. This is done to understand the nature and extent of the contamination and its potential consequences.

Current techniques involve gathering field samples, then packaging and transporting them to laboratories for analysis. This involves radioactive waste generation, shipping concerns and possibly sample contamination. An aid and/or possible alternative to current techniques involves in-situ, or field sampling. These techniques provide real time analyses of radioactive contaminants in the field without the added costs of preparing, shipping and analyzing samples.

A field radiation detector that provides real time results and can detect alpha, beta and gamma contamination in soil would be ideal for identifying and quantifying radionuclides. A detector of this type would have to detect the different physical interactions of all three radiation types. It would also have to be design to allow it to be bored into the earth's surface. The work presented here involves the initial characterization of just such a detector.

\subsection{Objectives:}

The four-fold objectives of this work were:

1. To design a gas flow proportional counter for in-situ soil characterization;

2. To construct a laboratory prototype to detect radioactive sources present in soil;

3. To determine operating voltage, pressure and dimensions of the detector; and

4. To characterize the detector's efficiency and energy resolution. 


\section{CHAPTER II \\ BACKGROUND}

\subsection{Recent Applications of Soil Monitoring}

Current research on measurements of radiation in soil is limited. Measurements of alpha contamination in soil are further limited. Hsu(1991), et al. researched Calcium Sulfate Thermoluminescent Dosimeters buried in soil to determine photon energies. These researchers used $\mathrm{CaSO}_{4}: \mathrm{Dy}$ in the power form, to monitor exposure rates in underground radiation fields. Their goal was to detect variations in the radiation field in natural soil, while maintaining stable measurements and maintenance-free measurement techniques. They took the dosimeters to a radwaste repository for low-level radioactive waste and monitored the radiation field. Their key finding that affected exposure rates was the variation in water content in soil or precipitation.

Miller (1994) et al. used above ground gamma-ray spectrometry to measure uranium in surface soils. This technique used high resolution germanium gamma-ray spectrometers to identify uranium isotopes and their progeny. Source geometry, activity per unit area and transport of nuclides downward in the soil were modeled. Fluences, dose rate in air and calibration factors were then calculated for uranium in surface soils. Surface concentrations using the in-situ technique were compared to soil samples. Their study indicated that typical natural background concentrations of uranium in soil would be measurable using a large $\mathrm{Ge}$ detector and a count time on the order of 30 minutes or less. Overall this study showed that the cost of soil treatment or removal can be reduced if measurements of certain radionuclides can be performed in the field as oppose to laboratory analysis.

Schilk (1994) et al. used plastic scintillating sensors placed directly on or above contaminated soil to observe and quantify high-energy beta particles that originate from the decay daughters of U-238 and Sr-90. These sensors were constructed by placing flat 
ribbons that were each composed of numerous square scintillating fibers and stacking these ribbons and coupling each bundled end to a photomultiplier tube. The photomultiplier tube was connected to electronic circuitry to measure coincident events. This is used to measure uranium and strontium in surface soils in the presence of coexisting fission products. Laboratory evaluations indicated those contamination levels less than $5 \mathrm{pCj} / \mathrm{g}$ can be determined within a few minutes, using this sensor.

Because alpha particles have short ranges in air, MacArthur(1992) et al. developed a long range alpha detector (LRAD) that uses a fan to move ions created by alpha particles over significant distances. Some proposed application of the LRAD is to monitor irregular surfaces or inside spaces smaller than an alpha probe's dimensions, to monitor larger surfaces and to detect low levels of contamination. However, for in-situ monitoring, a potential application of the LRAD in soil monitoring includes high-pressure air that is forced through the soil to carry ions to a remote anode.

Another application for in-situ monitoring is work done in Taiwan, Republic of China. Chao (1992) et al. monitored radioactive water using high-purity germanium detectors. The HPGe probe has a $15 \%$ HPGe detector and a multichannel analyzer to record the spectrum. Laboratory tests were performed to evaluate its operating depth, detecting sensitivity, detection volume and limits. A field operation was conducted in nuclear reactor pool water to measure radionuclide concentrations. For most radionuclides, the minimum detectable concentration values fell around $0.1 \mathrm{~Bq} / \mathrm{L}$ in a 10 hour measurement.

One final application of in-situ environmental monitoring is the electret ion chamber (EIC) researched by Fjeld (1994) et al. This electret ion chamber evaluated exposure measurements in the vicinity of Duke Power's Oconee Nuclear Station in South Carolina. Their main goals were to determine variability of the chamber and compare the chamber to TLDs and high pressured ion chamber measurements. The results of the study yield EIC measurements to be 6 to $7 \%$ higher than the high pressured ion chamber and the TLDs. Other conclusions revealed that radon entering the chamber must be minimized while the 
electret is being read and the radon entering the chamber during downtime in the field must be minimized.

\subsection{Introduction to Radiation Detectors}

Although there are many types of instruments to detect radiation, there are three major types to detect alpha, beta and gamma radiation. The three types include gas filled detectors, scintillators and semiconductor or solid state detectors.

Gas filled detectors include ionization chambers, proportional counters and GeigerMueller (GM) counters. These counters are based on interactions of charged particles with a counting gas. The ion chamber collects all charges created by direct ionization with the gas. When an electric field is applied, the drift of the positive and negative ions constitutes an electric current. If the rate of forming an ion pair is balanced with a loss rate, either by recombination, diffusion or migration, then this is a steady state current. This steady state current is an accurate measurement of the ionization current and is the basic principle behind direct current ion chambers. A very common application of ion chambers is the measurement of gamma ray exposure, however portable ion chambers are used as survey instrument for radiation monitoring purposes.

The proportional counter, at a higher voltage than the ion chamber, relies on the theory of gas multiplication to amplify the charge of the original ion pair. In an ideal proportional counter, each initial ionization produces several electrons from collision events. This is called an avalanche. It is assumed that the multiplication process is only through electron collision, i.e., photoelectric effects are neglected, no electrons are lost to negative ion formation and space charge effects are negligible. Finally gas multiplication is dependent on electron movement. Because gas multiplication is dependent on free electron movement and migration, fill gases must exhibit minimal electron attachment. An expanded section on proportional counter theory follows, since it is basic to this study. 
At the highest voltages of gas filled detectors are the Geiger-Mueller (G-M) counters. These counters produce pulses that are the same amplitude regardless of the number of original ion pairs. At a certain value of the electric field, an exponentially growing number of avalanches are created within a very short time. These avalanches are called Geiger discharges and ultimately terminate the chain reaction. This point is usually reached with the same number of avalanches, which relates to the same amplitude regardless of the number of ion pairs formed. Because this theory holds true a G-M counter cannot be applied to radiation spectroscopy. All the information of energy identification is loss in the avalanche process. However, advantages of G-M tubes are their almost $100 \%$ counting efficiency for charged particles entering the active volume.

Scintillators operate on the principle of converting the kinetic energy of charged particles directly into light and neutrons and electromagnetic radiation indirectly into light. This light is converted into an electrical signal through a photomultiplier (PM) tube and counted by electronics. Ideal scintillation material should have certain properties. They should convert the energy of charged particles into detectable light with a high efficiency and the light yield should be proportional to the deposited energy. This property would make good spectroscopy measurements. Where the scintillation material is coupled with the photomultiplier tube, its index of refraction should be near that of glass. This allows for efficient coupling of the scintillation light to the PM tube.

Scintillators are divided mainly into organic and inorganic types. Inorganics convert the kinetic energy of charged particles into detectable light better than organics because of the complicated $\pi$-electron structure of organics. The light yield is proportional to the energy deposited. For organics, luminescent states are instantaneously formed, so the decay time of the induced luminescence is short for organics compared to inorganics. For gamma ray spectroscopy, the preferred choice of scintillation material is inorganic crystals. Inorganic crystals have high atomic numbers, so gamma rays can be detected easier than with low- $Z$ numbers. The most widely used inorganic scintillator is sodium iodide (NaI). 
Organics, with low-Z numbers, are preferred for beta spectroscopy. Organic scintillators range from pure crystals to liquids and plastics. Each type of organic scintillator serves a unique purpose. Anthracene is a pure organic that has the highest scintillation efficiency of any organic scintillator. When counting low level beta activity or alpha particles liquid scintillators are useful. The source can be submerged into the liquid that allows an almost 100 percent counting efficiency. Plastic scintillators can be shaped and fabricated into different sizes. This flexibility makes them very useful. Finally, the major qualification of a good scintillation material is its ability to convert as much as possible of the incident radiation energy into detectable light.

The final category of detectors is semiconductor or solid state detectors. Radiation interacts with semiconductor material and causes excitation of electrons. This excitation allows electrons to leave a specific bonding site and drift throughout the crystal. The excitation process leaves a vacancy in the valence band, and produces an electron in the conduction band. If an electric field is applied to the semiconductor material, both the electrons and holes left behind will undergo a net migration. The electron hole pair is somewhat similar to the ion pair created in gas-filled detectors.

In charged particle spectroscopy, silicon is widely used. However, germanium is used in gamma-ray measurements. The main advantage of semiconductor detectors used in gamma ray spectroscopy is its resolution. Other advantages are that size can be smaller than gas-filled detector when measuring high-energy electrons or gamma rays due to its solid density.

\subsection{Introduction to Proportional Counters}

The proportional counter was first introduced by Rutherford and Geiger in 1908 (Wilkinson, 1950). However, it was not widely used until the late 1940s. In their simplest form the counters consist of a fine wire anode lying along the axis of a cylindrical cathode, the volume being filled with a gas. Figure 1 displays a conventional proportional counter. 


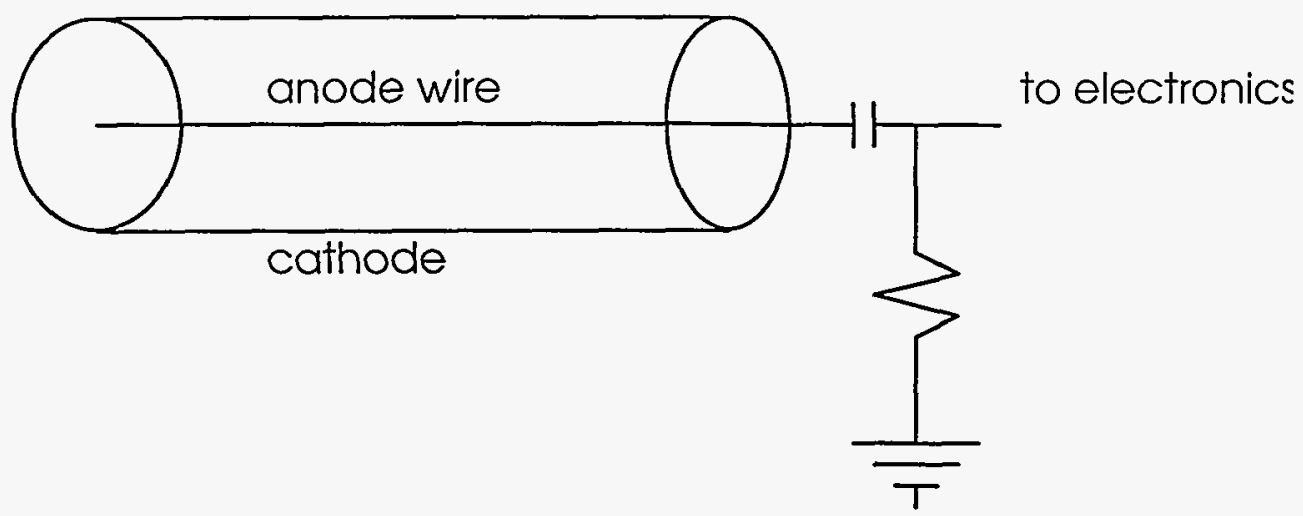

Figure 1. A Conventional Proportional Counter

The major component in proportional counter theory is gas multiplication. Detector performance is determined by energy resolution and efficiency. Voltage, pressure, space charge effects and spurious pulses characterize the detector operation. The following section discusses the theoretical aspects of the proportional counter.

\subsection{Proportional Counter Theory}

\subsubsection{Gas Multiplication, Fill Gases and Choice of Geometry}

Proportional counters rely on gas multiplication to amplify the number of electrons created by the initial interactions of the radiation with the fill gas. When ionizing radiation interacts with neutral molecules of the fill gas, electrons and positive ions are created. In the presence of an electric field, free electrons will migrate toward the positively charged anode. If the electron's kinetic energy is greater than the ionizing energy of a neutral gas molecule, then further ionizing may take place. This effect is called a Townsend avalanche.

In an ideal proportional counter, each initial ionization produces several electrons from collision events. This is the beginning of gas multiplication. The theory of gas multiplication in proportional counters is well documented (Akande 1992, Campion 1973, Genz 1973). The gas multiplication factor is dependent on pressure, applied voltage, geometry and design of the proportional tube and thus is important in proportional 
counter performance. Many experiments have been carried out to determine an expression of the gas multiplication factor (M). Hendricks (1972) studied the gas amplification factor of P-10 (90\% Argon, 10\% methane) and P-5 (95\% Argon, 5\% methane). He found that both gases equally obey the Diethorn equation (Equation 1), which is a widely used equation for the expression of the multiplication factor. It is assumed that the multiplication process is only through electron collision, e.g., photoelectric effects are neglected, no electrons are lost to negative ion formation and space charge effects are negligible. Given a cylindrical geometry and using methane gases, Diethorn (Knoll, 1987) derived a widely used expression for $M$ which is shown below.

$$
\ln M=\frac{V}{\ln (a / b)} * \frac{\ln 2}{\Delta V}\left(\ln \frac{V}{p a \ln (b / a)}-\ln K\right),
$$

where,

$$
\begin{aligned}
& \mathrm{M}=\text { gas multiplication factor } \\
& \mathrm{V}=\text { applied voltage (volts) } \\
& \mathrm{a}=\text { anode radius }(\mathrm{cm}) \\
& \mathrm{b}=\text { cathode radius or radius of the cylindrical geometry }(\mathrm{cm}) \\
& \Delta \mathrm{V}=\text { Potential difference through which an electron moves } \\
& \text { between successive ionizing events }(\mathrm{eV}) \\
& \mathrm{p}=\text { gas pressure }(\text { atm) } \\
& \mathrm{K}=\text { minimum value of electric field } \div \text { pressure }(\mathrm{V} / \mathrm{cm}-\mathrm{atm})
\end{aligned}
$$

Kiser(1960) has confirmed that Equation 1 adequately describes the gas amplification data for methane as well as Argon-Methane $\left(\mathrm{Ar}-\mathrm{Ch}_{4}\right)$ mixtures. Below some minimum value of $\mathrm{K}$, gas multiplication cannot occur and a measurable charge cannot be generated. The charge generated is related to $\mathrm{M}$ by the following expression:

$$
\mathrm{Q}=\mathrm{n}_{0} \mathrm{eM}
$$

$$
\begin{array}{ll}
\text { where, } & \mathrm{Q}=\text { total charge generated (coulombs) } \\
\mathrm{n}_{0}=\text { original ion pair } \\
\mathrm{e}=\text { electron charge (coulombs) } \\
\mathrm{M}=\text { gas multiplication factor }
\end{array}
$$


Measurements have been made to verify the validity of this expression, and values of $K$ have been reported by Wolff (1974). These values of $\mathrm{K}$ require high electrical fields. Fortunately, the cylindrical geometry chosen in this research is optimal in creating high electrical fields near the anode. For example, for a cylindrical geometry, the electric field at a some arbitrary radius $\mathrm{r}$ within the cylindrical geometry is given by

$$
\mathrm{E}(\mathrm{r})=\frac{V}{r} \ln \frac{b}{a}
$$

where, $\mathrm{a}=$ anode radius $(\mathrm{cm})$

$\mathrm{b}=$ cathode radius or radius of the cylindrical geometry $(\mathrm{cm})$

$\mathrm{V}=$ applied voltage (volts)

$E(r)$ is the electrical field where $r$ is the radius at which the electrical field is determined.

From Equation 3, when $r$ is small, large values of the electrical field can result. This large value of the electric field is a necessary requirement for gas multiplication to occur. The electric field is also determined by the diameter of the anode wire, applied voltage, cathode radius and r, which is the radius of the electrical field. Kageyama, et al. (1994) have researched characteristics of a single-wire proportional counter with a very thin cross section. Their detector consists of a $25 \mu \mathrm{m}$ diameter anode wire with an active volume of $40 \times 160 \mathrm{~mm}^{2}$. They investigated anode voltage in relation to the gas multiplication factor using P-10 at atmospheric pressure. Due to the small anode diameter they were able to create gas multiplication at very low values of applied voltage.

While the electrons accelerate to the anode, the positive ions, because of their size and momentum, slowly drift to the negatively charged cathode. If this positive charge is large, the electrical field can be distorted. This phenomenon is called space charge effects and can lead to poor energy resolution. Other factors that affect performance include mechanical defects of the anode wire. Non-uniformity in the wire can upset the proportionality of the gas multiplication process by distorting the otherwise uniform 
electric field. Another common cause of field distortion is the effect that occurs near the ends of the anode wire. Ion pairs created in this region undergo a degree of gas multiplication different from those created throughout the volume of the tube. Different methods have been developed to correct for electric fields near the ends of anode wires in proportional counters. Hortsman et al. (1973) uses concentric rings etched on nonconductive end plates that are set at suitable potentials to avoid distortion of the field. Finally gas multiplication is dependent on electron movement. Because gas multiplication is dependent on free electron movement and migration, fill gases must exhibit minimal electron attachment. For example, air is not an ideal proportional counter gas due to the high electron attachment of oxygen.

\subsubsection{Detector Efficiency}

Efficiency can be defined in two ways. Absolute efficiency is the ratio of the number of particles recorded divided by the number of particles emitted from the source as in:

$$
\text { efficiency }_{\text {abs }}=\frac{\text { number of pulses recorded }}{\text { number of radiation emmited by source }}
$$

Intrinsic efficiency is determined as the ratio of the number of particles recorded to the number of particles that cross the active volume as in:

$$
\text { efficiency }_{\text {int }}=\frac{\text { number of pulses recorded }}{\text { number of particles incident on detector }}
$$

Intrinsic efficiency is dependent on the detectors' characteristics, whereas absolute efficiency includes characteristics of counting geometry, attenuation and absorption, etc.

Ideally, for monoenergetic charged particles, such as alpha particles, all pulses from the detector are the same size. If the range of alpha particles is less than the thickness of the 
detector's active volume, all pulses should be detected resulting in an intrinsic efficiency of $100 \%$. However, alpha particles in soil are difficult to detect due to their very short range and complete absorption by very thin layers of soil. For example, the range of a $4.5 \mathrm{MeV}$ alpha particle in air is only about $3.75 \mathrm{~cm}$ (Radiological Health Handbook, 1980). Therefore, special considerations must be explored in this study to design an in situ radiation detector capable of detecting alpha particles in soil. The detector's wall must allow alpha particles to penetrate and interact in the active volume.

\subsubsection{Energy Resolution and Statistical Considerations}

Energy resolution performance is dependent on assuring that each electron formed is multiplied by the same factor in the gas multiplication process. This cascade is governed by the multiplication processes described above. Sipila, et al. (1976) found energy resolution values of $12.2 \%$ and $11.6 \%$, respectively, for $5.9 \mathrm{keV}$ photons in proportional counters using either $95 \%$ Argon $/ 5 \% \mathrm{C}_{2} \mathrm{H}_{2}$ (P-5) or a mixture of $95 \% \mathrm{Ne} 15 \%$ Argon. However, his work is limited to only energy resolutions of photons.

A common way of displaying energy resolution is through a differential pulse height spectrum (DPHS). Pulse magnitude, which is proportional to energy deposited in the detector, is plotted against the number of pulses observed. In ideal situations, if all pulses from the detector are the same size, the DPHS has a single isolated peak. However, because there are statistical considerations and other factors that affect energy resolution, the peak is not isolated but has a spread. The detector's energy resolution is determined from the Full Width at Half Maximum (FWHM) divided by the location of the peak centroid. The FWHM is a factor describing the statistical spread of the gaussian shaped peak. 


\section{CHAPTER III \\ THEORETICAL DESIGN CONCEPT AND DETECTOR CONSTRUCTION}

\subsection{Introduction}

The goal of this study was to design and construct a laboratory scale detector that could detect alpha radiation in soil. This study was divided into three parts or stages that accomplished that goal. The first stage consisted of determining the dimensions of the detector that were necessary for an operational proportional counter. This included applying the multiplication factor and theoretical design parameters to achieve measurement specifications of the detector. The second stage consisted of constructing a detector prototype. This stage took the theoretical design dimensions found in the first stage and applied them to construct a physical detector. This detector was coupled to electronics that provided real time measurements for an alpha source. In the last stage, the detector was tested to determine operating voltage, efficiency and energy resolution. This chapter discusses stages one and two.

\subsection{Design of the Detector}

\subsubsection{Choice of Geometry}

A cylindrical design was chosen, due to the need for high electric fields to produce gas multiplication. Because of the theoretical design concept, some factors in designing the detector could not be compromised. For example, gas pressure has to be approximately 1 atm due to the unsealed nature of the cathode and bias capabilities limited the voltage to 2000 volts. Certain parameters had to be establish for the proportional counter to work, they are listed in Table 1.

Table 1

Factors Affecting Design Process

\begin{tabular}{|c|c|}
\hline FACTORS & VALUES \\
\hline Pressure & $1 \mathrm{~atm}$ \\
\hline Electrical Field & $10^{6}$ Volts/meter \\
\hline Gas Multiplication Factor & must be $>1$, preferably $>100$ \\
\hline
\end{tabular}




\subsubsection{Application of the Multiplication Factor}

After considering the factors in Table 1, theoretical values were calculated using Equation 1 , as shown below.

$$
\ln M=\frac{V}{\ln (a / b)} * \frac{\ln 2}{\Delta V}\left(\ln \frac{V}{p a \ln (b / a)}-\ln K\right)
$$

In this equation, $\mathrm{K}$ and $\Delta \mathrm{V}$ depend on the gas composition. For a $\mathrm{P}-10$ gas mixture, $\mathrm{K}=$ $4.8 \times 10^{4} \mathrm{~V} / \mathrm{cm}^{*} \mathrm{~atm}$ and $\Delta \mathrm{V}=23.6 \mathrm{eV}$ (Wolff, 1974). Theoretical values of the voltage and multiplication factor are shown in Table 2.

Table 2

Theoretical Results of Voltage, Multiplication Factor and Electric Field

\begin{tabular}{|c|c|c|c|}
\hline VOLTAGE & LN M & $\begin{array}{c}\text { MULTIPLICATION } \\
\text { FACTOR }\end{array}$ & ELECTRIC FIELD \\
\hline Volts & & & Volts/Meter \\
\hline 1100 & 0.047 & 1.05 & 4842139 \\
\hline 1150 & 0.301 & 1.35 & 5062236 \\
\hline 1200 & 0.565 & 1.76 & 5282333 \\
\hline 1250 & 0.839 & 2.31 & 5502431 \\
\hline 1300 & 1.123 & 3.07 & 5722528 \\
\hline 1350 & 1.416 & 4.12 & 5942625 \\
\hline 1400 & 1.719 & 5.58 & 6162722 \\
\hline 1450 & 2.030 & 7.62 & 6382819 \\
\hline 1500 & 2350 & 10.49 & 6602917 \\
\hline 1550 & 2.679 & 14.56 & 6823014 \\
\hline 1600 & 3.014 & 20.37 & 7043111 \\
\hline 1650 & 3.358 & 28.72 & 7263208 \\
\hline 1700 & 3.709 & 40.80 & 7483306 \\
\hline 1750 & 4.067 & 58.39 & 7703403 \\
\hline 1800 & 4.432 & 84.13 & 7923500 \\
\hline 1850 & 4.805 & 122.07 & 8143597 \\
\hline 1900 & 5.183 & 178.28 & 8363694 \\
\hline 1950 & 5.569 & 262.07 & 8583792 \\
\hline & & & \\
\hline
\end{tabular}


After obtaining set theoretical values for $\Delta \mathrm{V}, \mathrm{K}, \mathrm{M}$ and a maximum applied voltage of 2000 volts, Excel spreadsheets were developed to find the best possible dimensions of the anode and cathode radius. These radii had to stay within the required factors of Table 1. The data in Table 2 are the final result of radii that satisfy the requirements. The results are for an anode wire radius of $0.0038 \mathrm{~cm}$ and the screened cathode radius of $1.905 \mathrm{~cm}$. The full data sheet is located in Appendix A.

Table 2 shows the theoretical values of the multiplication factor. Figure 2 shows the logarithmic dependence of $\mathrm{M}$ with applied voltage and suggests that voltages must be stable to avoid changes in the multiplication factor. In other words small changes in the voltage can result in an exponential increase in multiplication. Since stability is a necessity, this is not a desired effect in proportional counters.

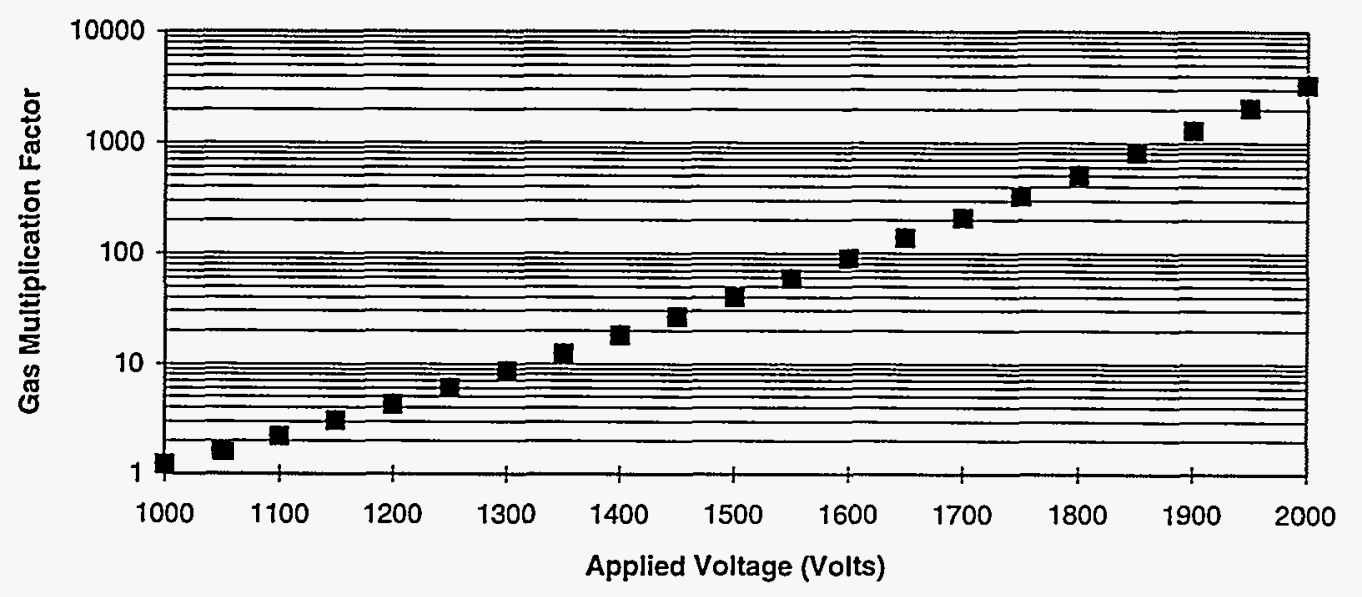

Figure 2

Multiplication Factor Versus Voltage 


\subsection{Detector Construction and Physical Characteristics}

\subsubsection{Materials Used}

The materials used to build the detectors were as follows:

* Two 1 1/4 inch PVC sch-40 caps - used as structural support for the cathode and SHV fitting

* Two \#8 rubber stoppers - used as structural support for the cathode

* Gutter screen - used as cathode

* Two $1 \mathrm{~cm}$ Plexiglas hollow cylinders - used as insulators between the rubber and anode and acted as field tubes

* One $0.0176 \mathrm{~cm}$ diameter platinum wire - used as the anode

* One SHV fitting - used as connection to the electronics

\subsubsection{Building the Detector}

One centimeter holes were drilled in the PVC caps and rubber stopper (refer to Figure 3). The Plexiglas tubes were placed through the rubber stoppers to insulate them from the anode wire. The top end of the anode wire, consisting of a thin platinum wire $0.0076 \mathrm{~cm}$ in diameter, was soldered to a standard high voltage (SHV) fitting located in the PVC cap, acting as the detector cap. The bottom end of the anode wire was grounded inside the bottom Plexiglas cylinder. The SHV fitting in the field tube was connected to the preamplifier and counting electronics described later in this work.

A $3.81 \mathrm{~cm}$ diameter cylindrical wire screen made of gutter screen surrounded the field tubes to serve as the cathode. Because alpha particles cannot penetrate this screen, a fraction of the screen acted as shielding for the Pu- 239 source. The Pu- 239 source used in this study has an area of $7.9 \mathrm{~cm}^{2}$. To arrive at a transmission factor, or one minus the fraction of the area taken up my the screened material, certain assumptions must be made. The first assumption is that the activity of the plated source is spread evenly over the entire area. Another assumption is that the screen cathode lies directly on this source. The 
transmission factor simply becomes the area of the screen cathode over the source divided by the area of the source subtracted by one. This equation is given by:

$$
\text { Transmission Factor }=1-\frac{\text { AreaofScreened }- \text { Cathode }}{\text { AreaofSource }}
$$

Due to the nature of the screened-cathode material it is difficult, at best, to find an exact area over the $\mathrm{Pu}-239$ source. However, our best estimates yield and area of $1.7 \mathrm{~cm}^{2}$. This was measured by using a micrometer to measure the thickness of the screen and using a ruler to measure the length. The area of the $\mathrm{Pu}-239$ source is $7.0 \mathrm{~cm}^{2}$, therefore, the transmission factor is $78.5 \%$. This means that $21.5 \%$ of the $\mathrm{Pu}-239$ alpha particles will be shielded from the detector by the cathode material.

The active volume of the detector varied, due to the anode wire length. The longer the length of the wire, the larger the active volume of the counter. One detector was constructed with an anode wire length of $2.54 \mathrm{~cm}$ and the other detector with an anode wire length of $7.62 \mathrm{~cm}$. The smaller detector had an active volume of $29.0 \mathrm{~cm}^{3}$ and the larger detector had an active volume of $87.1 \mathrm{~cm}^{3}$. These dimensions completed the proportional counter design. The detector is pictured in Figure 3 below.

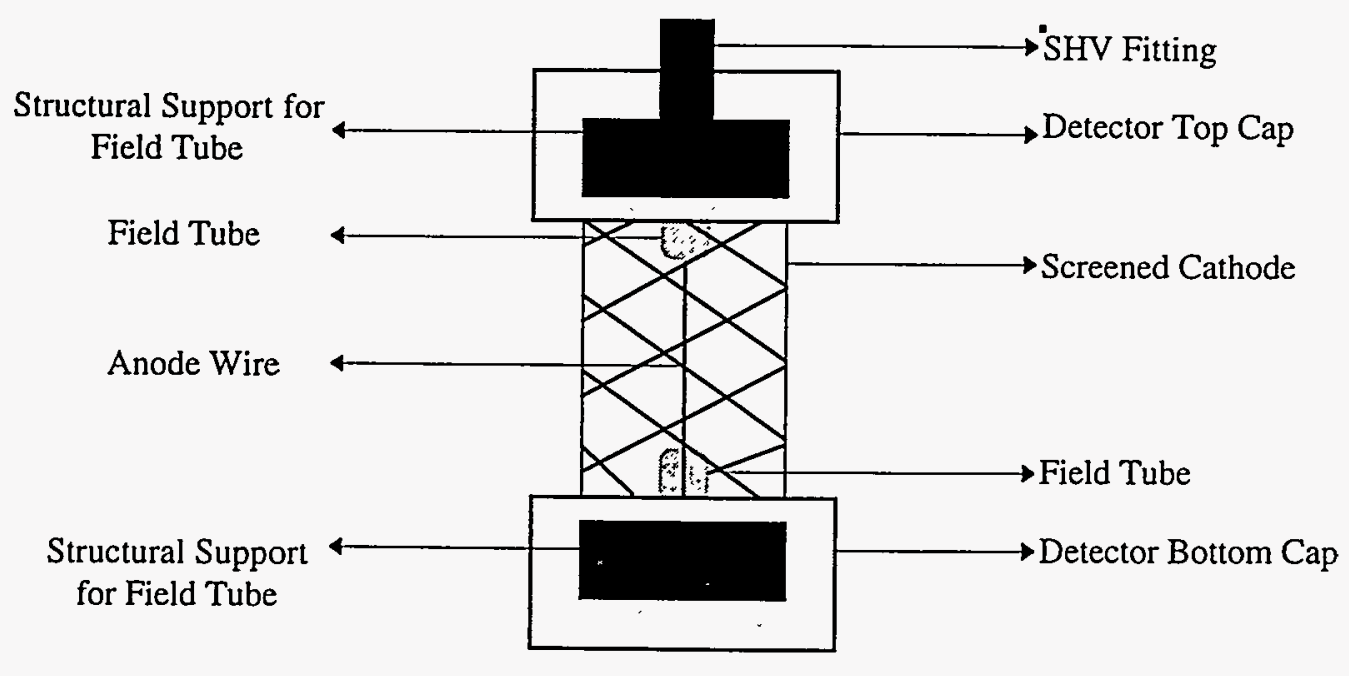

Figure 3.

Screened Cathode Gas Flow Proportional Counter 


\subsubsection{Fill Gas Application}

An additional service sleeve was drilled in the top PVC cap to allow for gas flow. The counting gas entered the detector through this sleeve. Tygon tubing was used to connect the detector to a pressurized gas cylinder. The gas pressure was maintained by a regulator. A low volume gas flow was supplied during data collection. The fill gas used was P-10 gas, which is composed of $90 \%$ Argon and $10 \%$ methane.

\subsubsection{Pulse Shaping and Processing}

The equipment used to process the pulse included the following:

* Ortec 478 Bias Supply 0-2 kV

* Ortec 142 PC Preamplifier

* Ortec 571 Linear Amplifier

* Computer Based Multichannel Analyzer

* Oscilloscope

The negative pulses from the detector were fed into the charge-sensitive preamplifier. One function of the preamplifier is to terminate the capacitance to maximize the signal-tonoise ratio. It also serves as an impedance matcher and to change the negative input pulse to a positive pulse. The positive pulse from the pre-amp was then feed into the linear amplifier. The linear amplifier serves to shape the pulse and amplify the signal. This pulse was fed to the computer based multichannel analyzer (MCA). The MCA converts the pulse amplitude (the analog signal) to an equivalent digital number that is then used as the basis for recording a pulse height spectrum. The computer-based multichannel analyzer program MAESTRO ${ }^{\text {tm }}$ was used to produce counting curve, efficiency and energy resolution data. MAESTRO ${ }^{\text {tm }}$ is a program designed by EG and G Ortec that simulates a multichannel analyzer. MAESTRO ${ }^{\mathrm{tm}}$, combined with an analog to digital converter and a personal computer can show spectra during real-time operating conditions. This computer program also generates efficiency and energy resolution data as requested by the user. 
The high voltage supply needed to produce multiplication was applied to the platinum anode wire of the proportional counter though the detector bias input connector. This connector is located on the preamplifier. To aid in pulse height spectra, an oscilloscope was used to display saturation limits. The oscilloscope was connected to the output of the linear amplifier. The electronic setup is shown in Figure 4 below.

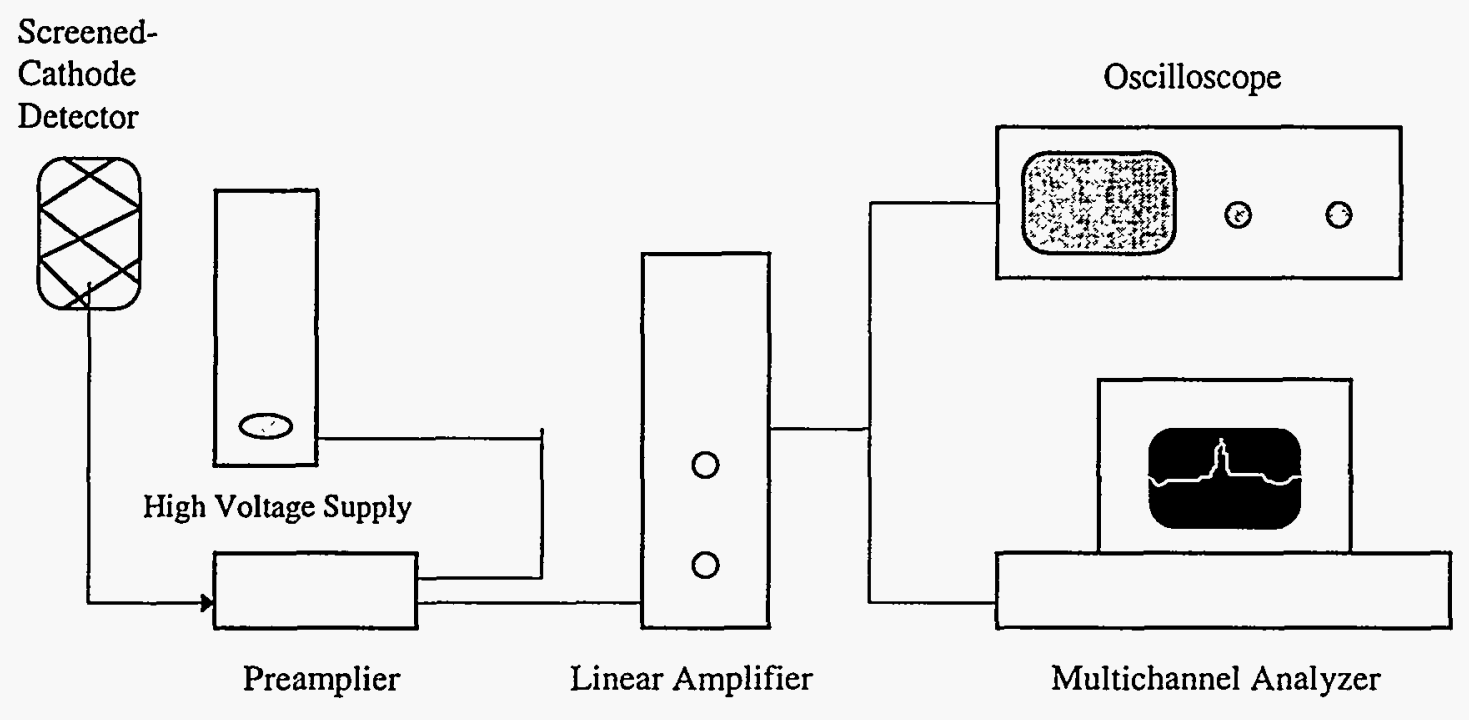

Figure 4

Electronic Setup

\subsubsection{Laboratory Detector Setup}

A cylindrical void was made in moist soil by inserting a $3 \mathrm{~cm}$ diameter wooden dowel into the center of a container of test soil obtained from the University of Michigan plant services. A pure Pu-239 source was taped to the outer surface of the screened cathode. The detector was placed inside the void and connected to the electronics (see Figure 3). The complete laboratory set up is illustrated in Figure 5. Data collection was achieved 
after the gas filling system was turned on and the detector and soil void was flushed with the counting gas. A low volume gas flow was supplied during data collection.

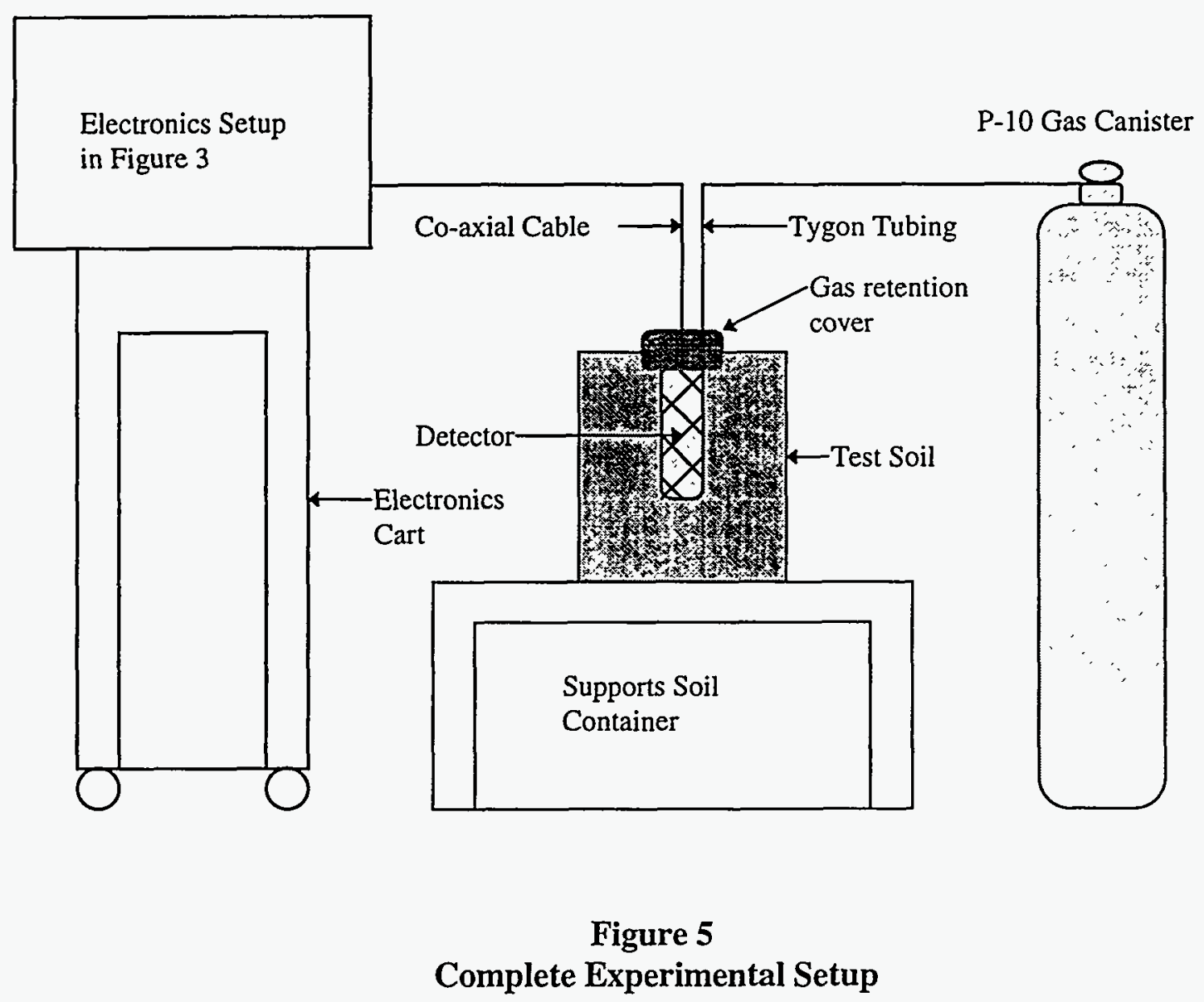




\section{CHAPTER IV \\ EXPERIMENTAL METHODS}

\subsection{Introduction}

After designing and building the detector (stages one and two), experimental results were determined. This chapter summarizes the methods use to accomplish stage three of the study. Initially, radioactive soil was to be used as the earth's media, however a pure Pu239 source was used to simulate radioactive soil and test the detector. First, an operating voltage was determined to assure the counter was operating in the proportional region. Next background measurements were taken to establish a base-line radiation level. Finally energy resolution and detector efficiency were determined for the screened-cathode detector. The values of detector efficiency and energy resolution from the proportional counter were compared to those from a silicon detector.

\subsection{Establishing Operating Voltage}

To establish a counting curve, the experimental setup in Figure 5 was operated with a pressure of $1 \mathrm{~atm}$ of $\mathrm{P}-10$ gas. The experimental procedure began three minutes after the gas was allowed to enter the detector and soil void. This ensured that no impurities, such as air, were in the active volume. These impurities would interfere with the multiplication process. Using MAESTRO ${ }^{\mathrm{m}}, 60$ second count rates were recorded as voltage was varied from 750 to 2000 volts. The curve from these data produced an area of near-zero slope, or plateau, where small changes in applied voltage did not change gas multiplication appreciably. The operating voltage was chosen based on these results. The results are shown in Chapter 5. 


\subsection{Measuring Background of the Soil, Efficiency and Energy Resolution}

Whether measuring background or emissions from the Pu-239 source, the same experimental technique was used with the exception of the placement of the Pu-239 source on the detector. Background measurements were made with a 60 second count rate at a pressure of $1 \mathrm{~atm}$ with an operating voltage of 1975 volts. The detector's background counts were made periodically throughout the data collection procedure.

Numerous data were taken to achieve efficiency and energy resolution. The detector was often taken apart from its fill gas system and electronic package and reassembled to verify reproducibility. The net and gross count rate were recorded as well as dead time, oscilloscope observations and location of peak centroid.

\subsection{Determining Minimum Detectable Activity}

To determine the minimum detectable activity of the proportional counter, methods devised by Currie (1967) were applied to the detector and counting geometry. The range of an alpha particle in soil was calculated and applied to the large detector's volume to obtain an approximation of an activity per gram. 


\section{CHAPTER V \\ VOLTAGE, EFFICIENCY AND ENERGY RESOLUTION RESULTS}

\subsection{Introduction}

Chapter 5 introduces stage three of this study, the determination of operating voltage, efficiency and energy resolution. These results were accomplished in different phases. Each phase consisted of a different counting geometry. Phase one had a counting geometry that consisted of the small volume detector with the $\mathrm{Pu}-239$ source placed in the soil void. Counting curves, detector efficiency and energy resolutions were gathered from this detector geometry. After phase one results, phase two goals were to change the counting geometry to achieve a better counting efficiency. Phase two consisted of mounting the source to the outside of the detector's cathode, instead of in the soil void. This phase was used only to established a counting curve. Due to further insight into the research, a larger volume detector was constructed. This was the beginning of phase three. The Pu-239 source was again mounted to the outside of the detector screen using the large volume detector. Phase three consisted of developing a counting curve and determining efficiency and energy resolution.

\subsubsection{Characteristics of the $\mathrm{Pu}-239$ Source}

Plutonium-239's half-life is 24,000 years. Table 3 lists the most prominent decays of $\mathrm{Pu}-$ 239 their percent yield and energy. The complete Pu-239 decay scheme is located in Appendix B. The plutonium source used for this study is a $11 / 4$ inch diameter plated source of $0.0096 \mu \mathrm{Ci}$ as of July 14, 1971. With a half-life of tens-of-thousands of years, decay correction was not applied and the source was assumed to contain $0.0096 \mu \mathrm{Ci}$ for measurements in this work.

Table 3

List of Prominent Decay Energies of Pu-239

\begin{tabular}{|c|c|c|}
\hline Radiation & Yield (Bq/sec) & Energy (MeV) \\
\hline Alpha & $10.7 \%$ & 5.105 \\
\hline Alpha & $15.2 \%$ & 5.143 \\
\hline Alpha & $73.8 \%$ & 5.156 \\
\hline
\end{tabular}




\subsubsection{Background measurements of the detector}

Background counts were collected before and after measurements were made with the Pu239 source attached to the detector or placed in the soil. Background counts were obtained by placing the detector in the bored hole without a source and counting for 60 seconds. Figure 6 displays a background counting spectrum. Complete data are located in Appendix C.

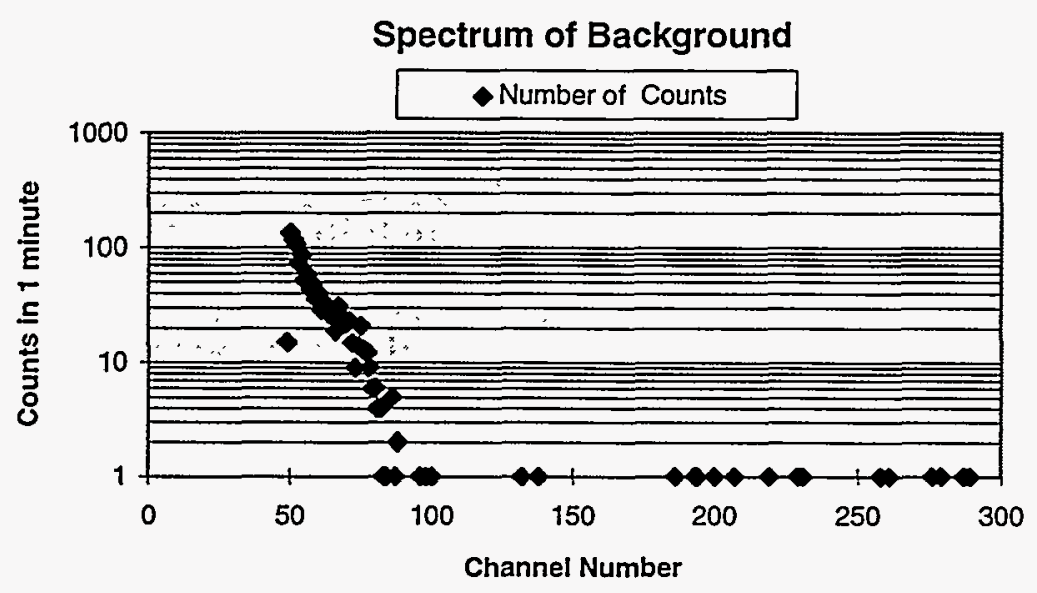

Figure 6

Background Counts of Detector without Pu-239

From the Figure of the background spectrum, the number of counts dropped off drastically after channel 100 . At this point, the count rate for each channel was near zero. Channel number 100 was used as the baseline channel for counts associated with the $\mathrm{Pu}$ 239 source.

\subsection{Counting Curves of Pu-239}

\subsubsection{Counting Curve for Small Detector with Source in Bored Hole}

Table 4 presents the counting curve data for the source in the bored hole for the small detector. These counting curve data started at 1600 volts and ended with 1900 volts in increments of 1000 volts. 
Table 4

Counting Curve for Pu-239 Source Bored in Hole

\begin{tabular}{|c|c|}
\hline Voltage (Volts) & Gross Counts \\
\hline 1600 & 0 \\
\hline 1700 & 47 \\
\hline 1800 & 247 \\
\hline 1900 & 285 \\
\hline
\end{tabular}

In Table 4, the observed data displayed counts of 0 gross counts to a maximum of 285 gross counts in a one minute count time. The low count number could be due to the placement of the source in the dirt, which is farther from the detector. This low count is expected because of the range that the alpha particles were required to travel to be detected. The count rate was shown to be higher if the source was attached directly to the cathode. Further measurements of the counting curve applied such geometry. The implications of these observations are discussed in Chapter 6. From the data in Table 4 a counting curve was developed. The curve is pictured below in Figure 7.

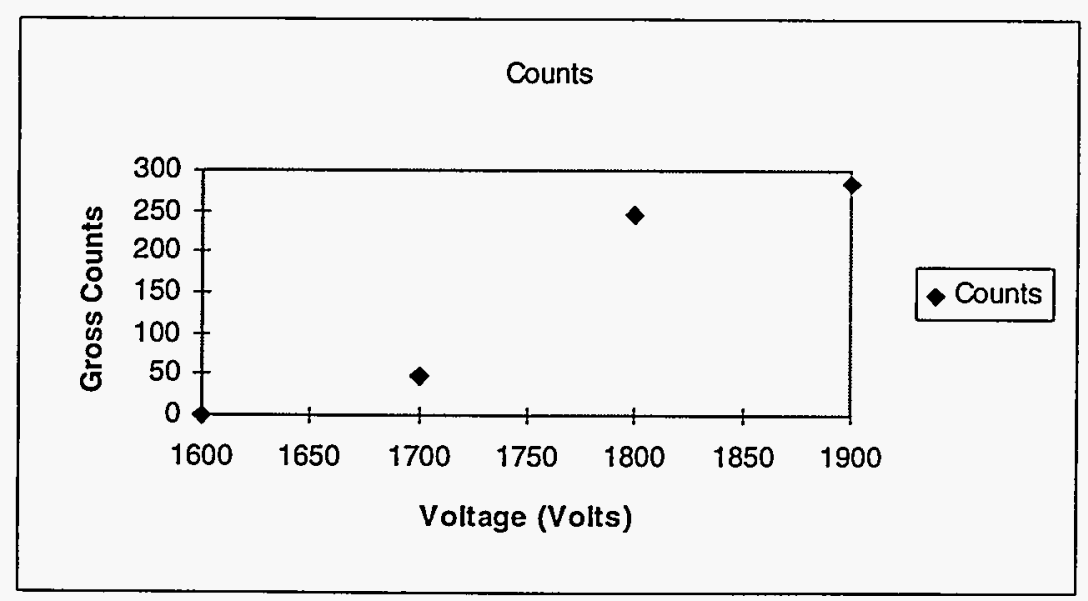

Figure 7

Counting Curve of Pu-239 Source Placed in Bored Hole 
Figure 7 displays the total gross counts of the small detector. Since theoretical values suggested an operating voltage around 1750 volts, measurements were taken up to 1900 volts. After careful consideration, future counting curves included measurements up to 2000 volts and smaller increments. The operating plateau on this Figure is between 1800 and 1900 volts.

\subsubsection{Counting Curve for the Small Detector with Source Attached to Cathode}

A continuation of this phase resulted in a counting curve for the small detector with the source mounted to the outside of the cathode screen. Table 5 shows the counting curve data for the source taped to the cathode of the small detector. From Table 5, the observed data displayed 0 gross counts to a maximum of 6118 gross counts in one minute. From the data in Table 5 a counting curve was developed. This curve is pictured below in Figure 8.

Table 5

Counting Curve Data for the Small Detector with Source Taped to Cathode

\begin{tabular}{|c|c|c|c|}
\hline Voltage (volts) & Gross Counts & Voltage (volts) & Gross Counts \\
\hline 1475 & 0 & 1750 & 2490 \\
\hline 1500 & 54 & 1775 & 3314 \\
\hline 1525 & 104 & 1800 & 3723 \\
\hline 1550 & 197 & 1825 & 4083 \\
\hline 1575 & 357 & 1850 & 4608 \\
\hline 1600 & 881 & 1875 & 4673 \\
\hline 1625 & 545 & 1900 & 5147 \\
\hline 1650 & 1339 & 1925 & 5327 \\
\hline 1675 & 1998 & 1950 & 5735 \\
\hline 1700 & 2802 & 1975 & 6003 \\
\hline 1725 & 2490 & 2000 & 6118 \\
\hline
\end{tabular}


Figure 8 displays the total gross counts taken in one minute. Counts were observed around 1400 volts; however, the plateau began to level off around 1975 volts. The operating plateau is greater than 1950 volts. Therefore an applied voltage of 1975 volts was chosen to represent the operating voltage for this detector. The complete counting curve data are located in Appendix D.

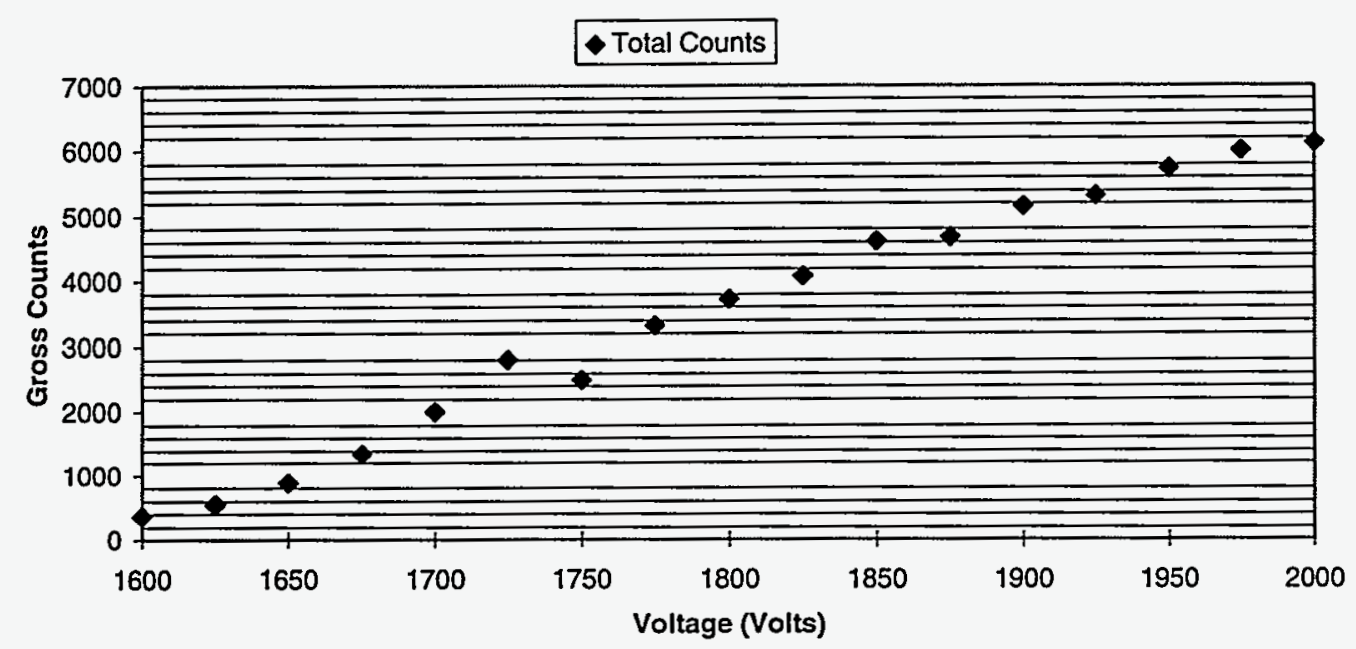

Figure 8

Counting Curve for the Small Detector

\subsubsection{Counting Curve for the Large Detector with Source Attached to Cathode}

Table 6 supplies the counting curve data for the large detector. The large detector's active volume has an anode wire length of $7.62 \mathrm{~cm}$ with all other dimensions similar to those of the smaller detector. This counting curve data started at 750 volts and ended with 2000 volts in increments of 50 volts. 
Table 6

Counting Curve Data for the Large Detector

\begin{tabular}{|c|c|c|c|}
\hline Voltage (Volts) & Gross Counts & Voltage (Volts) & Gross Counts \\
\hline 750 & 0 & 1400 & 1669 \\
\hline 800 & 2 & 1450 & 1959 \\
\hline 850 & 2 & 1500 & 2053 \\
\hline 900 & 34 & 1550 & 2296 \\
\hline 950 & 55 & 1600 & 2655 \\
\hline 1000 & 96 & 1650 & 5722 \\
\hline 1050 & 270 & 1700 & 7268 \\
\hline 1100 & 219 & 1750 & 7731 \\
\hline 1150 & 271 & 1800 & 8298 \\
\hline 1200 & 485 & 1850 & 8600 \\
\hline 1250 & 856 & 1900 & 9129 \\
\hline 1300 & 1251 & 1950 & 9043 \\
\hline 1350 & 1282 & 2000 & 9370 \\
\hline
\end{tabular}

The observed data (Table 6) ranged from 0 gross counts to a maximum of 9370 gross counts in one minute. From the data, a counting curve was developed. The curve is pictured below in Figure 9.

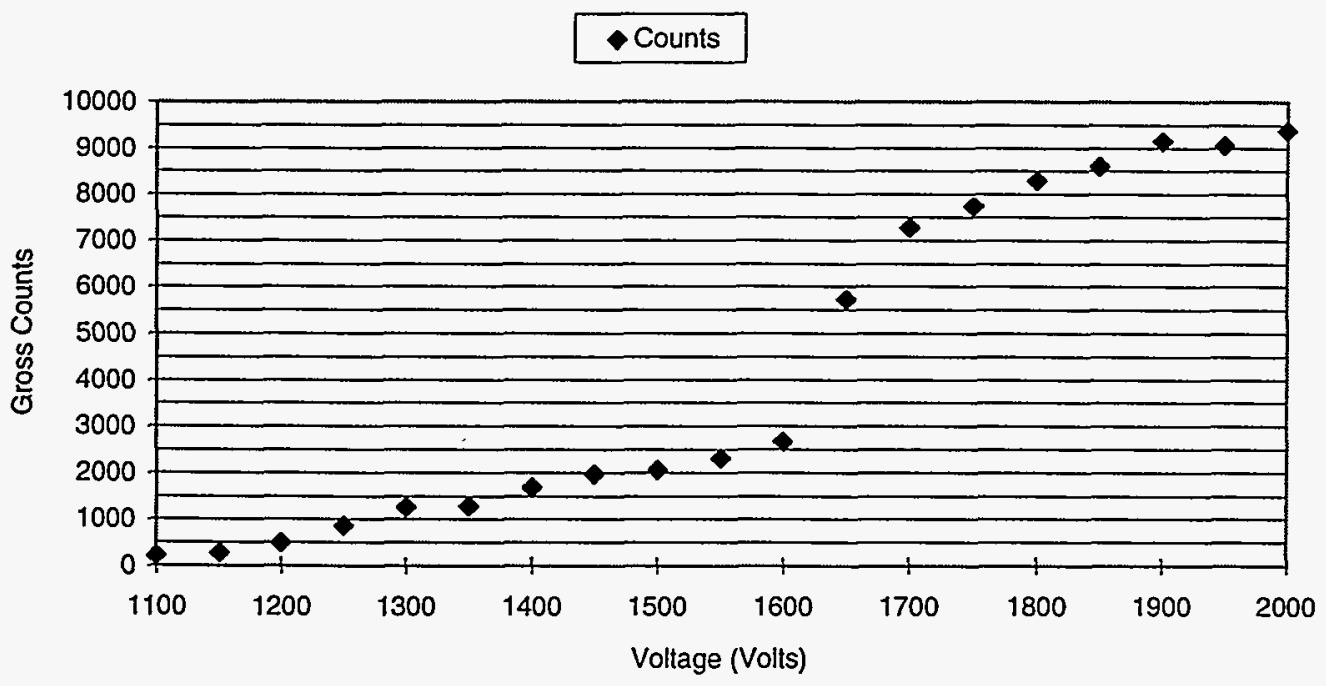

Figure 9

Counting Curve for the Large Detector 
Figure 9 displays the total gross counts of the large detector. Counts were observed at lower applied voltages in the large volume detector. Counts were observed around 800 volts, and could be associated with more noise from the detector probe. Because the active volume was larger, due to the longer gutter screen, imperfections in the screen could have resulted in distortions in the electric field. These imperfections could have been due to bends that resulted in routine handeling of the detector probe. This distortion in the electric field could have produce fields of high intensity were ionizations could have been amplified and counted to a greater extent than would normally occur. However, the plateau began to level off around 1900 volts. The operating plateau is between 1900 and 2000 volts. Therefore, 1975 volts was chosen to represent the operating voltage for this detector.

\subsection{Detector Efficiency of Pu-239}

Efficiency tells us how well the detector can detect radiation and convert that to a useful signal. Absolute efficiency is the ratio of the number of particles recorded divided by the number of particles emitted from the source and is given by:

$$
\text { efficiency }_{\mathrm{abs}}=\frac{\text { number of pulses recorded }}{\text { number of radiation pulses emmited by source }}
$$

Intrinsic efficiency is dependent on the detectors' characteristics, such as cathode and anode radii. It is the number of pulses recorded divided by the number of alpha particles incident on the detector. Since the small and larger detector counting characteristics are the same, intrinsic efficiency should be the same for each detector. Efficiency values quoted herein are those of absolute efficiency.

The following data, in Table 7 , show a sample of efficiency data for two counting geometries that were performed in phases one and three. Phase two consisted of only counting curve data. The large volume detector had the Pu-239 source attached directly 
to the cathode, whereas, the $\mathrm{Pu}-239$ plated source was located in the bored hole when measurements of the smaller detector were taken. This table is a representation of the range of efficiency data. Section 5.5 discusses the mean, standard deviation and variances of the data. The complete experimental data are located in Appendix E.

Table 7

A Sample of Efficiency Data

\begin{tabular}{|c|c|c|}
\hline Detector Setup & Gross Counts & Efficiency \\
\hline $\begin{array}{c}\text { Small Detector } \\
\text { Source in Bored Hole }\end{array}$ & & \\
\hline 1 & 285 & 2.7 \\
\hline 2 & 269 & 2.5 \\
\hline 3 & 293 & 2.7 \\
\hline 4 & 289 & 2.4 \\
\hline 5 & 259 & \\
\hline Larger Detector \\
Source Taped to Cathode & & 57.6 \\
\hline 1 & 6187 & 70.5 \\
\hline 2 & 7575 & 77.3 \\
\hline 3 & 8307 & 83.5 \\
\hline 4 & 8978 & 90.9 \\
\hline 5 & 9763 & \\
\hline
\end{tabular}

The efficiency of the large detector ranged from $57.9 \%$ to $90.9 \%$ with an average efficiency of $76.7 \%$. This detector's geometry consisted of the source being mounted to the cathode. The efficiency of the small detector ranged from $2.4 \%$ to $2.7 \%$ with an average efficiency of $2.6 \%$. The efficiency is low for the small detector due to the source being approximately 0.5 inches from the detector and partially covered by dirt. These two factors resulted in the amount of activity that entered the active volume being lower than 
expected. Another factor for both detectors was the cathode screen attenuation. Efficiency data quoted in Table 7 are a sample of the results of actual counts of detected radiation divided by the radiation emitted from the source. The screen cathode material provided shielding against the source and blocked out alpha particles that might otherwise have been detected. Because alpha particles cannot penetrate this screen, a fraction of the screen acted as shielding for the Pu-239 source. The transmission factor discussed in chapter 3 was $78.5 \%$, which is the same for the two source geometries. If this factor is added to the efficiency of the larger detector, a $98.2 \%$ efficiency results. This is expected for a proportional counter of this geometry. Other observations that alter the efficiency of the detector are discussed in more detail Chapter 6.

\subsection{Energy Resolution of Pu-239}

A common way of displaying energy resolution is through a differential pulse height spectrum (DPHS). In ideal situations, if all pulses from the detector are the same size, the DPHS has a single isolated peak. However, because there are statistical considerations and other factors that affect energy resolution, the peak is not isolated but has a spread. The detector's energy resolution is determined from the Full Width at Half Maximum (FWHM) divided by the location of the peak centroid in terms of channel number. Again as in detector efficiency, energy resolution was found for the source taped to the cathode for the larger detector and for the source bored in the hole for the smaller detector.

\subsubsection{Energy Resolution for Small Detector}

A spectrum for determining energy resolution for the small detector is pictured in Figure 10. Here, the channel number is plotted against the number of counts or pulses in each channel. This is a typical pulse height spectrum used to estimate energy resolution. Factoring in the background spectrum, only counts after channel 100 were considered part of the Pu-239 source pulses. 


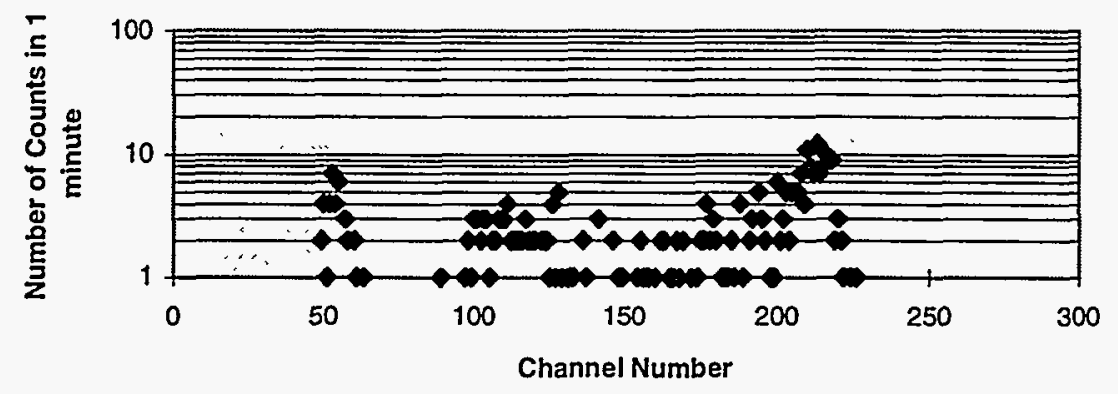

Figure 10

Spectrum of Pu-239 at 1900 Volts

Two distinct peaks were observed and their origin is discussed in Chapter 6. The centroid location for the first and second peak respectively were channel number 120 and 200 . Energy resolution ranged from $0.9 \%$ to $2.5 \%$ for the small peak and $2.8 \%$ to $6.0 \%$ for the larger peak. Energy resolution data for the source bored in the hole are located in Table 8. This resolution is taken from data at 1900 volts, because this was the initial operating voltage for the smaller detector.

Table 8

Energy Resolution for Small Detector

\begin{tabular}{|c|c|c|c|c|c|c|}
\hline $\begin{array}{c}\text { Experimen } \\
\text { tal Data \# }\end{array}$ & $\begin{array}{c}\text { FWHM } \\
\text { Small } \\
\text { Peak }\end{array}$ & $\begin{array}{c}\text { Centroid } \\
\text { Location }\end{array}$ & $\begin{array}{c}\text { Energy } \\
\text { Resolution } \\
\%\end{array}$ & $\begin{array}{c}\text { FWHM } \\
\text { Large } \\
\text { Peak }\end{array}$ & $\begin{array}{c}\text { Centroid } \\
\text { Location }\end{array}$ & $\begin{array}{c}\text { Energy } \\
\text { Resolution } \\
\%\end{array}$ \\
\hline 1 & 1.3 & 128 & $\mathbf{1 . 0}$ & 9.9 & 214 & 4.7 \\
\hline 2 & 1.2 & 102 & $\mathbf{1 . 2}$ & 5.9 & 215 & $\mathbf{2 . 8}$ \\
\hline 3 & 1.5 & 117 & $\mathbf{1 . 3}$ & 12.0 & 202 & $\mathbf{6 . 0}$ \\
\hline 4 & 1.1 & 124 & $\mathbf{0 . 9}$ & 9.9 & 215 & $\mathbf{4 . 6}$ \\
\hline 5 & 2.6 & 104 & $\mathbf{2 . 5}$ & 6.4 & 201 & $\mathbf{3 . 2}$ \\
\hline
\end{tabular}




\subsubsection{Energy Resolution for Large Detector}

The energy resolution estimate for the large detector consisted of different shaped spectra. As measurements were taken for the large detector, the detector's resolution appeared to worsen (as shown in Figure 18). Again factoring in the background spectrum in Figure 6, the peaks after channel 100 were considered part of the Pu-239 source pulses. Figure 11 displays several spectra for the large detector taken on different days.

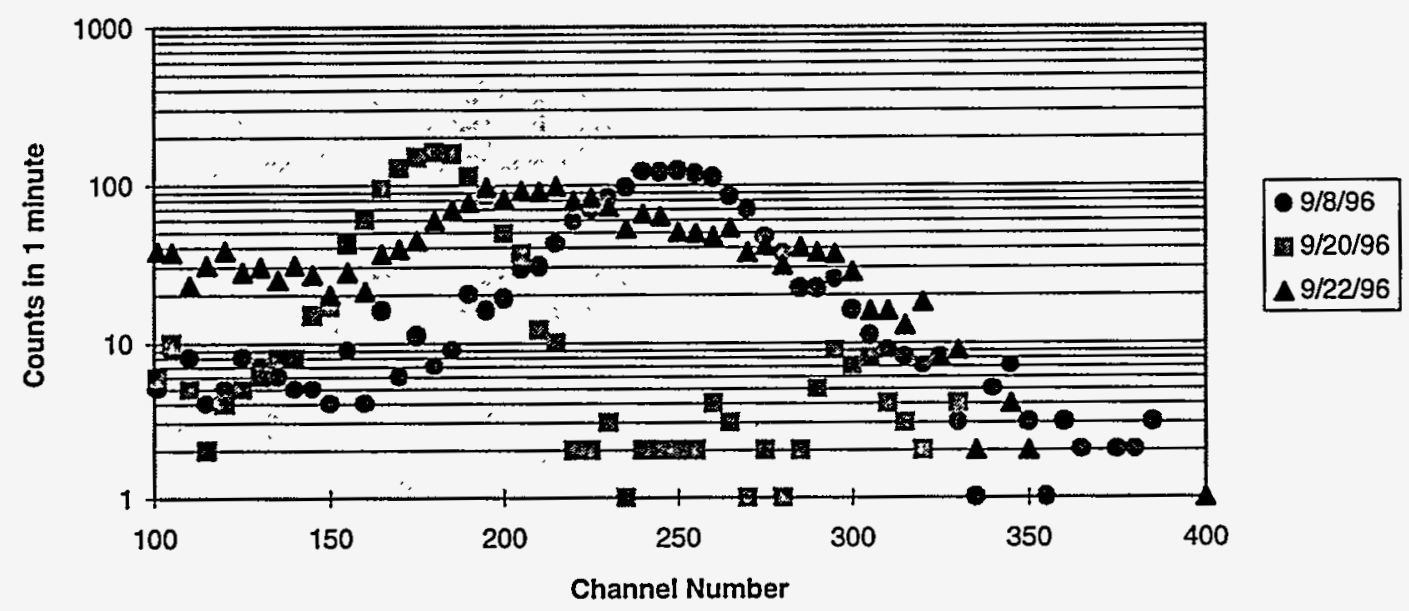

Figure 11

Spectrum of Pu-239 at 1975 Volts on Different Days

In Figure 11, the spectrum taken on 9/8/96 displayed a centroid location around channel number 250 , with a resolution ranging from $14 \%$ to $16 \%$. As measurements went along, the energy resolution worsened. The other two spectra show energy resolution obtained on different days. One spectrum has a centroid location around channel number 175 and continues with counts in channels 250 to 325 . The other spectrum seems to have no distinct peak and continues to produce pulses up to channel number 350 . The implications of these variations are discussed in Chapter 6. A sample of FWHM, peak centroid and their corresponding energy resolutions is located in Table 9. The full data are located in Appendix E. 
Table 9

Energy Resolution for Large Detector

\begin{tabular}{|c|c|c|c|c|c|c|}
\hline $\begin{array}{c}\text { Experimen } \\
\text { tal Data \# }\end{array}$ & $\begin{array}{c}\text { FWHM } \\
\text { Small } \\
\text { Peak }\end{array}$ & $\begin{array}{c}\text { Centroid } \\
\text { Location }\end{array}$ & $\begin{array}{c}\text { Energy } \\
\text { Resolution } \\
\%\end{array}$ & $\begin{array}{c}\text { FWHM } \\
\text { Large } \\
\text { Peak }\end{array}$ & $\begin{array}{c}\text { Centroid } \\
\text { Location }\end{array}$ & $\begin{array}{c}\text { Energy } \\
\text { Resolution } \\
\%\end{array}$ \\
\hline 1 & 28.1 & 291 & 9.7 & 19.8 & 217 & 9.1 \\
\hline 2 & 14.7 & 266 & 5.5 & 15.1 & 215 & 7.1 \\
\hline 3 & 15.4 & 260 & 5.9 & 13.0 & 215 & 6.0 \\
\hline 4 & 27.5 & 268 & 10.3 & 17.3 & 216 & 8.0 \\
\hline 5 & 16.3 & 259 & 6.3 & 14.7 & 216 & 6.8 \\
\hline 6 & 17.9 & 260 & 6.9 & 16.3 & 217 & 7.5 \\
\hline 7 & 1.0 & 255 & 0.4 & 16.6 & 218 & 7.6 \\
\hline 8 & 5.6 & 253 & 2.2 & 18.0 & 217 & 8.3 \\
\hline 9 & 1.7 & 254 & 0.7 & 16.2 & 218 & 7.4 \\
\hline 10 & 15.1 & 250 & 6.0 & 18.1 & 219 & 8.3 \\
\hline
\end{tabular}

\subsection{Statistics of Counting Data}

Radiation measurements are subject to statistical uncertainty due to the random nature of radioactive decay and instability of electronic devices. The amount of uncertainty can be compared to predictions of statistical models. The Poisson distribution is the statistical model of choice because it is the classic model for radioactive decay and it is more specialized than the normal distribution.

A main goal of this thesis was to provide a reproducible detector. The experimental process consisted of setting the detector in the soil void to take measurements for efficiency and energy resolution. The detector was then removed from its experimental setup and applied again to verify reproducibility. This process allowed for reproducibility, but the statistical uncertainty of removing the detector coupled with the random nature of radioactive decay is difficult to model. 
The Chi-square test was performed on the data to verify observed fluctuations were consistent with expected statistical fluctuations. In order to use the Chi-square test, we assumed that the detector was kept in a constant location and that measurements were continually taken with minimum deviation of the experimental setup. Mean, predicted and actual standard deviation and variances were found for detector efficiency and energy resolution. The Chi-square test was applied to the data to compare the sample variances with expected variances.

From the data in Appendix $\mathrm{C}$, the following were calculated:

Experimental Mean

$$
\mu=\left(\frac{1}{n}\right) \sum_{i} x
$$

Sample Variance

$$
\mathrm{s}^{2}=\left(\frac{1}{n-1}\right) \sum_{i}(x-\mu)^{2}
$$

Standard Deviation

$$
\sigma \equiv \longdiv { \mu }
$$

\section{Chi-Square}

$$
\mathrm{X}^{2}=(n-1) \frac{s^{2}}{\mu}
$$

where, $\mu=$ mean

$\mathrm{n}=$ sample size

$\mathrm{x}=$ trial numbers

$\mathrm{s}^{2}=$ sample variance

$\sigma=$ standard deviation 
Using these formulae, Table 10 was constructed.

Table 10

Mean, Standard Deviation, Variances and Chi-Square of Data

\begin{tabular}{|c|c|c|c|c|c|}
\hline & MEAN & $\begin{array}{c}\text { STANDARD } \\
\text { DEVIATION }\end{array}$ & VARIANCE & $\begin{array}{c}\text { CHI- } \\
\text { SQUARE }\end{array}$ & $\begin{array}{c}\text { PROBABILITY } \\
\mathbf{p}\end{array}$ \\
\hline $\begin{array}{c}\text { SMALL } \\
\text { DETECTOR }\end{array}$ & & & & & \\
\hline Efficiency & 2.59 & 0.12 & 0.018 & 0.028 & $<0.005$ \\
\hline $\begin{array}{c}\text { Energy } \\
\text { Resolution } \\
\text { Small Peak }\end{array}$ & 4.24 & 1.28 & 1.64 & 1.55 & $0.25<\mathrm{p}<0.50$ \\
\hline $\begin{array}{c}\text { Energy } \\
\text { Resolution } \\
\text { Large Peak }\end{array}$ & 1.37 & 0.66 & 0.44 & 1.29 & $0.25<\mathrm{p}<0.50$ \\
\hline $\begin{array}{c}\text { LARGE } \\
\text { DETECroR }\end{array}$ & & 10.81 & 116.78 & 36.53 & $0.95<\mathrm{p}<0.98$ \\
\hline \begin{tabular}{c} 
Efficiency \\
\hline $\begin{array}{c}\text { Energy } \\
\text { Resolution }\end{array}$
\end{tabular} & 76.71 & 17.75 & 14.74 & 18.95 & $0.25<\mathrm{p}<0.50$ \\
\hline
\end{tabular}

In Table 10, the average efficiency is $2.59 \pm 0.12 \%$ and $76.71 \pm 10.81 \%$ for the small volume and large volume detectors, respectively. The average energy resolution for the low energy peak of the small detector is $4.24 \pm 1.28 \%$ and for the high energy peak is $1.37 \pm 0.66 \%$. The large detector's energy resolution and efficiencies were $17.75 \pm$ $3.74 \%$ and $76.71 \pm 10.81 \%$.

The Chi-square results fluctuated. From Table 10, the specific value of the probability, $\mathrm{p}$ is defined as the probability that a random sample from a true Poisson distribution would have a larger value of chi-square than the value shown on the table. For example, the probability that a random sample from a true Poisson distribution would have a larger degree of fluctuation than the efficiency of the small proportional counter is less than 0.005 , which is a very small probability. This value was interpolated from the chi-square table in Appendix C. Very low probabilities indicate abnormally large fluctuations in the data. In Table 10, the small standard deviation and variance for the small detector could 
have been due to the small number of samples that made up the average mean. A total of five samples were used to compute the data. A discussion of the statistical power is presented in Chapter 6 . However, the energy resolution was promising with a probability between 0.25 and 0.50 . A perfect fit to Poisson distributions would yield a probability of 0.50 .

As for the larger detector, the efficiency chi-square indicated a probability between 0.95 and 0.98 . This was a very high probability. This probability tells us that a true Poisson distribution would have a much larger value of chi-square, so the data show abnormally small fluctuations. The standard deviation and variances for the large detector did not agree with the obserbed probability. As with the small detector, a limited size of 25 sample measurements could provide limited statistical power. This issue is discussed in Chapter 6. Likewise the energy resolution for the large detector had a chi-square of 18.95 , this represents a probability of 0.25 to 0.5 degree of fluctuations. An overall assessment of the chi-square test is a check of the counting system to see if observed fluctuations are consistent with expected statistical fluctuations.

\subsection{Minimum Detectable Activity}

Detection limits for proportional counters as well as any instrument, are useful to determine optimization of measurement procedures. They also provide guides in establishing regulatory policy. To determine the minimum detectable limit in terms of activity, it is necessary to define and make assumptions that coincide with the radioactive process. Currie (1967) developed methods to define limits for qualitative detection and quantitative determination of radioactivity. One method estimated the lower limit of detection (LLD), the true net signal level which may be expected to lead to detection. The equation is :

$$
\operatorname{LLD} \text { (counts) }=2.71+\left[4.65 * \mu_{\mathrm{b}}\right]
$$

where $\mu_{\mathrm{b}}$ is the standard deviation of the background counts 
Certain assumptions have been made for this equation to hold true. The counting time for background and the source must be the same. The source must follow a poisson distribution and be an independent and random sample. One of the well known detection limits is called the minimum detectable activity or MDA. It is the activity level that accounts for all factors of an instrument's characteristics. Not only is background considered, but efficiency of the detector, counting time, self absorption and decay corrections are factors that govern the MDA. An equation for the MDA is:

\section{$\mathrm{MDA} \leq\{\mathrm{LLD}[$ counts $]\} /\{$ Detector Efficiency*2.22[dpm/pCi] $\}$}

To arrive at some minimum activity per volume or a minimum detectable concentration, a range of alpha particles in soil is necessary to compute the amount of particles that can reach the active volume. The range of alpha particles in any medium may be computed from the following equation:

$$
\text { Range }\left(\mathrm{mg} / \mathrm{cm}^{2}\right)=0.56 \mathrm{~A}^{1 / 3} \mathrm{R} \text {, }
$$

where, $A=$ atomic number of the medium, $R=$ range of the alpha particle in air in $\mathrm{cm}$

The range of a $4.5 \mathrm{MeV}$ alpha particle is $3.5 \mathrm{~cm}$ (Radiological Health Handbook). Assuming a typical silty soil containing $30 \%$ water and $20 \%$ air by volume, the atomic number of the soil composition is 21.14 (Environmental Protection Agency, Federal Guidance Report No. 12). Using the range equation above and a density of $1.6 \mathrm{~g} / \mathrm{cm}^{3}$ for the soil yields a range of $3.39 \times 10^{-3} \mathrm{~cm}$ for a $4.5 \mathrm{MeV}$ alpha particle in soil. Using the active volume of the large detector as a standard volume, the effective volume for calculating a MDA is $0.136 \mathrm{~cm}^{3}$ of soil.

When calculating the LLD and MDA of the gas flow proportional counter, certain assumptions to arrive at these calculations were not representative of the theoretical method used to derive these terms. Measuring background of the gas flow proportional counter yield no background counts; however, the counts of the $0.0096 \mu \mathrm{Ci} \mathrm{Pu}-239$ 
source attached to the cathode of the larger detector yield an average of 8000 counts per minute. Ideally, using the activity of the Pu-239 source and the volume of the soil would result in an activity of the soil of no greater than approximately a microcurie per cubic centimeter. Estimating counts on the magnitude of 10 times lower than the actual counting rate of 8000 counts per minute, would produce a MDA of no better than a nanocurie per gram. 


\section{CHAPTER VI \\ DISCUSSION OF RESULTS}

\subsection{Introduction}

This preliminary study of the screened-cathode gas flow proportional counter was focused toward demonstrating the concept of an inground wall-less detection system. The intent of this chapter is to discuss what was accomplished here and what further studies need development. This chapter discusses complications in the theoretical procedure of designing the detector and problems encountered during construction of a prototype. Complications arising from the experimental procedures to produce data are also of concern. Discussions of the counting curves of both detectors, efficiency and energy resolution are presented here. Recommendations for continuation of this study and ideas for future studies complete the discussion.

\subsection{Discussion of Results}

\subsubsection{Problems Encountered with Design and Construction of a Prototype}

Because proportional counter operation relies on gas multiplication, a major concern in designing the proportional counter was the value of $M$. Because this is a unique proportional counter, specific multiplication data are not yet published. However there are published data on the multiplication factor of some proportional counters, but the variables, whether they are pressure, or tube dimensions are not completely the same. This study's goal was to use a multiplication factor around 100. This $\mathrm{M}$ value underestimated the actual value of the operation voltage. The theoretical value was around 1750 volts, but the experimental value was 1975 volts. A useful continuation of this study would be to measure and publish multiplication factors of this screened cathode detector. 
The limitation of voltage made it almost impossible to work with the required anode wire. Soldering the wire to the SHV fitting was extremely cumbersome, added to the fact that if excessive tension was placed on the wire, it would easily break. A temporary solution was to solder the wire and allow it to hang on its own weight without tension from anything else. The cathode material, made of gutter screen, was easily bent. When placing the cathode material in the detector cap, it bent under pressure and did not allow for a complete cylindrical cathode. Solutions to these problems are to apply a higher voltage to the detector, so the anode radius size can increase and to use a more sturdy material for the cathode.

The original thought of the proportional counter was to place the single anode wire into a bored hole in the soil to detect radiation. Theory suggested that with proper grounding, the soil itself would act as the cathode. With this detector setup, a high voltage was applied to the anode wire and pulses were counted. The pulses were assumed to be from radiation emissions originating from inside the surface of the bored hole. However, an extremely high number of pulses resulted. This was determined to be due to noise generated because of the range of the electrical field. The electrical field extended from the anode wire to the ground wire that was estimated to set about 2 inched from the anode wire. It is theorized that negative ions in the soil migrated to the anode wire and produced the added pulses. The cathode screen was then place around the detector to provide a defined electrical field. This resulted in a much reduced noise component.

The final major problem in designing and constructing the detector was the gas flow system. The gas flowed into the detector through the top and out through the cathode screen. Because there was not a barrier or channel for the gas to flow, it went to the atmosphere. The detector needs a barrier to slow down the flow to the atmosphere, but a detector designed with a recycling system would be optimal. 


\subsubsection{Discussion of Counting Curve, Efficiency and Energy Resolution}

\subsubsection{Counting Curves}

The two detectors were different in only the anode wire length, which changed the active volume of the detector. This difference is independent of the operating voltage needed and should therefore be the same for the two detectors. Counting curves revealed that the operating voltage should be between 1900 and 2000 volts. An operating voltage of 1975 was chosen to represent the proportional counter operating voltage. All measurements were consistent with counting curve theoretical expectations. One limitation in the counting curve data was the inability to go above 2000 volts with the current instrumentation. Measurements above this voltage would verify the detector is truly proportional. After the proportional region, a steep rise in the counting curve is expected. These regions are called the limited proportional and Geiger-Mueller (GM) regions. A verification of these regions with the counter would provide extra assurance of the proportional counter regions. Another advantage of a higher voltage is the possibility of beta and gamma counting curves. Acquiring additional instrumentation allowing higher applied voltage is of definite need for future work.

\subsubsection{Detector Efficiency}

From the decay scheme in Appendix B, 100\% of the alpha radiation from the Pu-239 source were approximately the same energy and range, the counter could easily record each particle that entered the active volume. Therefore, efficiency could easily reach $100 \%$. The average efficiency was only $76.7 \%$. This decrease in efficiency could be due to a number of factors. One such factor is the placement of the flat Pu-239 source against a cylindrical cathode. The Pu-239 source was placed against the cathode, however the edges of the source were not in direct contact with the active volume. Another source of decreased efficiency was the attenuation or shielding of the cathode material itself. The screened material provided shielding against alpha particles might otherwise have been 
detected. However, due to the screen shape, the area was difficult to determine. The transmission factor quoted in this study can be improve by using material that allows an accurate measurement of the area.

\subsubsection{Energy Resolution}

Energy resolution in this proportional counter seems to be the hardest to reproduce. The smaller detector has better resolution. The most critical geometric factor was the uniformity and smoothness of the anode wire and screen cathode diameter. The better resolution in the smaller detector could be due to the less wire and cathode area, meaning

less room for error. Another possible decrease in resolution for the larger detector could be due to anode wire aging. The large detector experienced more counting time than the smaller one. Research has shown that proportional counters can show aging effects. One such cause of aging effects is the gradual buildup of solid deposits on the anode wire from trace contaminates of the fill gases. These trace contaminants could have lead to nonuniformity of the anode wire, thus decreasing resolution.

\subsection{Conclusions}

The goal of this study was to design and build a laboratory scale detector that could detect alpha radiation in soil. For theoretical design specifications, the Diethorn equation was applied to find the best possible dimensions for the proportional counter. These dimensions were applied to construct a detector. Two gas flow proportional counters were constructed. The counters are cylindrical with a radius of $1.905 \mathrm{~cm}$ and have an anode wire radius of $0.0038 \mathrm{~cm}$. The active volume of the small detector was $29.0 \mathrm{~cm}^{3}$ and the active volume for the larger detector was $87.1 \mathrm{~cm}^{3}$.

Initially, radioactive soil was to be used as the earth's media, however a pure Pu-239 source was used to simulate radioactive soil and test the detector. First measurements consisted of an operating-voltage determination to assure the counter was operating in the 
proportional region. An operating voltage of 1975 volts was experimentally determined. Next background measurements were taken to establish a base-line radiation level. Finally energy resolution and detector efficiency were determined for the screened-cathode detector. The average efficiency was $2.6 \%$ and $76.7 \%$ for the small and large volume detectors, respectively. The average energy resolution of the low-energy peak of the small detector was $4.2 \%$ and for the higher-energy peak was $1.4 \%$. The energy resolution for the large detector was $17.76 \%$.

The Chi-square test was performed on the data to verify observed fluctuations were consistent with expected statistical fluctuations. Overall standard deviations and variances conflicted with the Chi-square probability. Possible problems or conclusions from this experiment may be due to (1) the small sample size with extremely limited statistical power, (2) the uncertainty about what constitutes an appropriate sample size, the appropriate counting time and duration of the experiment and/or (3) the limited data to compare with prior quantitative data on proportional counter duration and stability.

\subsection{Future Studies}

There are a number of studies that need development from this concept of a wall-less detection system. Because multiplication factors for this unique counter are not yet measured, a continuation of this study can be to experimentally determine multiplication factors. Applying higher voltages to the screened counter can allow for calibrating the detector using alpha, beta and gamma sources. This will also produce counting curves and operating voltages for beta and gamma radiations.

Redesigning the gas flow system for the screened-cathode counter is a major consideration along with experimenting with different fill gases. Since fill gases have different drift velocities for ions, a faster drift velocity might improve energy resolution. Boring methods must also be researched to find the best methods of applying the detector to the soil and seasonal variations such as soil moisture and temperature might cause variations. 
There are numerous other applications and studies to be done to this screened cathode gas flow proportional counter. The ultimate goal would be to finalize the detector for industrial application and use. This would entail researching industries methods of quoting proportional counter data and ensuring those qualifications are met. Using radioactive soil, instead of pure sources to test these qualifications would be optimal because this is indicative of real life radioactive sites. To measure radiation in this manner is the ultimate goal for this detector. 


\section{CHAPTER 7 \\ CONTRIBUTION TO HEALTH PHYSICS and LONGTERM SIGNIFICANCE}

This detector technology applied proportional counter theory to present day environmental problems. The application of a wall-less gas flow radiation detection system, similar to the one studied in this work, will potentially improve radioactive site characterization and cleanup. Radiation exposure will be decreased due to the limited amount of personnel needed to quantify and qualify radioactive contamination. Exposures from handling during shipping and transport is also eliminated. Sample contamination will be prevented because no laboratory samples are required to determine concentrations. This further eliminates costly lab analyses of hundreds of samples. The generation of radioactive waste will be decreased because wastes from samples containers, storage and shipment containers will be decreased.

Overall, this detector technology will emphasize health and safety for workers and will provide cost effective cleanup of radiologically contaminated sites. It also will allow infield determination of whether clean-up goals have been achieved and can be used to monitor clean areas for unintentional radioactive spills. Finally, it can be used in emergency-response situations were rapid assessment of deposited activity and exposure rates for specific radionuclides are desired. 
Appendix A

Gas Multiplication Data 
Multiplication Factor Theortical Data

\begin{tabular}{|c|c|c|c|c|c|c|c|c|c|c|c|c|}
\hline & & & & & & & & & & & & \\
\hline & $\mathrm{cm}$ & $\mathrm{cm}$ & & & & & & & & & & Anode \\
\hline Volts & $a$ & $b$ & $\ln (b / a)$ & DelfaV & $p$ & $K$ & $\ln M$ & Volts & $M$ & Electrical & $\mathrm{V} / \mathrm{m}$ & inches \\
\hline 550 & 0.0038 & 0.75 & 5.285072 & 23.6 & 1 & $4.80 E+04$ & -1.71522 & 550 & 0.179924 & 27385.97 & 2738597 & 0.009652 \\
\hline 600 & 0.0038 & 0.75 & 5.285072 & 23.6 & 1 & $4.80 E+04$ & -1.58102 & 600 & 0.205765 & 29875.61 & 2987561 & 0.009652 \\
\hline 650 & 0.0038 & 0.75 & 5.285072 & 23.6 & 1 & $4.80 E+04$ & -1.42364 & 650 & 0.240836 & 32365.24 & 3236524 & 0.009652 \\
\hline 700 & 0.0038 & 0.75 & 5.285072 & 23.6 & 1 & $4.80 E+04$ & -1.24486 & 700 & 0.28798 & 34854.87 & 3485487 & 0.009652 \\
\hline 750 & 0.0038 & 0.75 & 5.285072 & 23.6 & 1 & $4.80 \mathrm{E}+04$ & -1.04622 & 750 & 0.351262 & 37344.51 & 3734451 & 0.009652 \\
\hline 800 & 0.0038 & 0.75 & 5.285072 & 23.6 & 1 & $4.80 E+04$ & -0.82904 & 800 & 0.436467 & 39834.14 & 3983414 & 0.009652 \\
\hline 850 & 0.0038 & 0.75 & 5.285072 & 23.6 & 1 & $4.80 \mathrm{E}+04$ & -0.59449 & 850 & 0.551846 & 42323.78 & 4232378 & 0.009652 \\
\hline 900 & 0.0038 & 0.75 & 5.285072 & 23.6 & 1 & $4.80 \mathrm{E}+04$ & -0.34357 & 900 & 0.70923 & 44813.41 & 4481341 & 0.009652 \\
\hline 950 & 0.0038 & 0.75 & 5.285072 & 23.6 & 1 & $4.80 \mathrm{E}+04$ & -0.07722 & 950 & 0.925687 & 47303.04 & 4730304 & 0.009652 \\
\hline 1000 & 0.0038 & 0.75 & 5.285072 & 23.6 & 1 & $4.80 E+04$ & 0.203769 & 1000 & 1.226014 & 49792.68 & 4979268 & 0.009652 \\
\hline 1050 & 0.0038 & 0.75 & 5.285072 & 23.6 & 1 & $4.80 \mathrm{E}+04$ & 0.498655 & 1050 & 1.646505 & 52282.31 & 5228231 & 0.009652 \\
\hline 1100 & 0.0038 & 0.75 & 5.285072 & 23.6 & 1 & $4.80 \mathrm{E}+04$ & 0.806778 & 1100 & 2.240676 & 54771.95 & 5477195 & 0.009652 \\
\hline 1150 & 0.0038 & 0.75 & 5.285072 & 23.6 & 1 & $4.80 \mathrm{E}+04$ & 1.127535 & 1150 & 3.088035 & 57261.58 & 5726158 & 0.009652 \\
\hline 1200 & 0.0038 & 0.75 & 5.285072 & 23.6 & 1 & $4.80 E+04$ & 1.460377 & 1200 & 4.307584 & 59751.21 & 5975121 & 0.009652 \\
\hline 1250 & 0.0038 & 0.75 & 5.285072 & 23.6 & 1 & $4.80 E+04$ & 1.804801 & 1250 & 6.078759 & 62240.85 & 6224085 & 0.009652 \\
\hline 1300 & 0.0038 & 0.75 & 5.285072 & 23.6 & 1 & $4.80 E+04$ & 2.160341 & 1300 & 8.674099 & 64730.48 & 6473048 & 0.009652 \\
\hline 1350 & 0.0038 & 0.75 & 5.285072 & 23.6 & 1 & $4.80 \mathrm{E}+04$ & 2.526572 & 1350 & 12.51055 & 67220.12 & 6722012 & 0.009652 \\
\hline 1400 & 0.0038 & 0.75 & 5.285072 & 23.6 & 1 & $4.80 \mathrm{E}+04$ & 2.903096 & 1400 & 18.2305 & 69709.75 & 6970975 & 0.009652 \\
\hline 1450 & 0.0038 & 0.75 & 5.285072 & 23.6 & 1 & $4.80 E+04$ & 3.289546 & 1450 & 26.83068 & 72199.38 & 7219938 & 0.009652 \\
\hline 1500 & 0.0038 & 0.75 & 5.285072 & 23.6 & 1 & $4.80 E+04$ & 3.68558 & 1500 & 39.86822 & 74689.02 & 7468902 & 0.009652 \\
\hline 1550 & 0.0038 & 0.75 & 5.285072 & 23.6 & 1 & $4.80 E+04$ & 4.090877 & 1550 & 59.79229 & 77178.65 & 7717865 & 0.009652 \\
\hline 1600 & 0.0038 & 0.75 & 5.285072 & 23.6 & 1 & $4.80 E+04$ & 4.505139 & 1600 & 90.48092 & 79668.28 & 7966828 & 0.009652 \\
\hline 1650 & 0.0038 & 0.75 & 5.285072 & 23.6 & 1 & $4.80 \mathrm{E}+04$ & 4.928086 & 1650 & 138.1149 & 82157.92 & 8215792 & 0.009652 \\
\hline 1700 & 0.0038 & 0.75 & 5.285072 & 23.6 & 1 & $4.80 E+04$ & 5.359454 & 1700 & 212.6089 & 84647.55 & 8464755 & 0.009652 \\
\hline 1750 & 0.0038 & 0.75 & 5.285072 & 23.6 & 1 & $4.80 \mathrm{E}+04$ & 5.798996 & 1750 & 329.9681 & 87137.19 & 8713719 & 0.009652 \\
\hline 1800 & 0.0038 & 0.75 & 5.285072 & 23.6 & 1 & $4.80 E+04$ & 6.246478 & 1800 & 516.1916 & 89626.82 & 8962682 & 0.009652 \\
\hline 1850 & 0.0038 & 0.75 & 5.285072 & 23.6 & 1 & $4.80 E+04$ & 6.701679 & 1850 & 813.7713 & 92116.45 & 9211645 & 0.009652 \\
\hline 1900 & 0.0038 & 0.75 & 5.285072 & 23.6 & 1 & $4.80 E+04$ & 7.164392 & 1900 & 1292.575 & 94606.09 & 9460609 & 0.009652 \\
\hline 1950 & 0.0038 & 0.75 & 5.285072 & 23.6 & 1 & $4.80 \mathrm{E}+04$ & 7.634417 & 1950 & 2068.165 & 97095.72 & 9709572 & 0.009652 \\
\hline 2000 & 0.0038 & 0.75 & 5.285072 & 23.6 & 1 & $4.80 E+04$ & 8.111568 & 2000 & 3332.798 & 99585.36 & 9958536 & 0.009652 \\
\hline 2050 & 0.0038 & 0.75 & 5.285072 & 23.6 & 1 & $4.80 E+04$ & 8.595666 & 2050 & 5408.168 & 102075 & 10207499 & 0.009652 \\
\hline 2100 & 0.0038 & 0.75 & 5.285072 & 23.6 & 1 & $4.80 \mathrm{E}+04$ & 9.086542 & 2100 & 8835.576 & 104564.6 & 10456462 & 0.009652 \\
\hline 2150 & 0.0038 & 0.75 & 5.285072 & 23.6 & 1 & $4.80 \mathrm{E}+04$ & 9.584034 & 2150 & 14530.92 & 107054.3 & 10705426 & 0.009652 \\
\hline 2250 & 0.0038 & 0.75 & 5.285072 & 23.6 & 1 & $4.80 \mathrm{E}+04$ & 10.59826 & 2250 & 40065.04 & 112033.5 & 11203353 & 0.009652 \\
\hline
\end{tabular}


Appendix B

Decay Scheme of Pu-239 


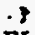

HALFLIFE = 24065 YEARS

DECAY MODE(S): a

\begin{tabular}{|c|c|c|c|}
\hline RADIATION & $\begin{array}{c}y(i) \\
(B q-3)^{-1} \\
\end{array}$ & $\begin{array}{c}E(i) \\
(\mathrm{MeV})\end{array}$ & $\mathrm{y}(\mathrm{i}) \times \mathrm{E}(\mathrm{i})$ \\
\hline$\alpha 44$ & $\overline{1.07 \bar{E}-01}$ & $5.105 \mathrm{E} 00$ & $5.45 E-01$ \\
\hline$\alpha$ recoil & $1.07 E-01$ & 8.695E-02 & $9.29 E-03$ \\
\hline$a 46$ & $1.52 \mathrm{E}-01$ & $5.143 \mathrm{E} \quad 00$ & $7.83 E-01$ \\
\hline$\alpha$ recoil & $1.52 \mathrm{E}-01$ & 8.760E-02 & $1.33 E-02$ \\
\hline$\therefore 47$ & $7.38 \mathrm{E}-01$ & $5.156 \mathrm{E} \quad \infty$ & $3.80 \mathrm{E} \quad 00$ \\
\hline a recoil & $7.38 \mathrm{E}-01$ & $8.781 E-02$ & $6.48 E-02$ \\
\hline$\alpha \quad 48$ & $1.21 E-03$ & $5.156 E 00$ & $6.24 E-03$ \\
\hline$\alpha$ recoil & $1.21 E-03$ & $8.781 \mathrm{E}-02$ & $1.06 E-04$ \\
\hline$\gamma 1$ & $9.99 E-01$ & $7.300 \mathrm{E}-05$ & $7.29 \mathrm{E}-05$ \\
\hline ce-M, y 2 & $1.09 E-01$ & $8.637 E-03^{*}$ & $9.39 E-04$ \\
\hline $\mathrm{ce}-\mathrm{N}^{+}, \gamma^{2}$ & $7.13 \mathrm{E}-02$ & $1.294 \mathrm{E}-02^{-}$ & $9.23 E-04$ \\
\hline$\gamma 4$ & $5.86 \mathrm{E}-05$ & $3.869 E-02$ & $2.27 E-06$ \\
\hline$c e-L_{1}, \gamma 4$ & $2.09 E-03$ & $1.693 \mathrm{E}-02$ & $3.54 E-05$ \\
\hline ce-Ln, $\gamma 4$ & $1.36 E-02$ & $1.774 \mathrm{E}-02$ & $2.42 E-04$ \\
\hline$c e-L_{3}$, y 4 & $-1.22 E-02$ & $2.152 E-02$ & $2.62 E-04$ \\
\hline ce-M, y 4 & $7.61 \mathrm{E}-03$ & $3.439 E-02$ & $2.62 \mathrm{E}-04$ \\
\hline $\mathrm{ce}-\mathrm{N}^{+}, \gamma 4$ & $2.93 E-03$ & $3.869 \mathrm{E}-02^{\circ}$ & $1.13 \mathrm{E}-04$ \\
\hline y 8 & $2.08 E-04$ & $5.162 E-02$ & $1.07 \mathrm{E}-0.5$ \\
\hline$c e-L_{1}$, y 8 & $8.88 E-04$ & $2.986 \mathrm{E}-02$ & $2.65 E-05$ \\
\hline$c e-I_{m, 1} \gamma 8$ & $2.55 E-02$ & $3.067 \mathrm{E}-02$ & $7.83 \mathrm{E}-04$ \\
\hline$c e-L_{31}$ y 8 & $2.15 E-02$ & $3.445 E-02$ & $7.40 \mathrm{E}-04$ \\
\hline 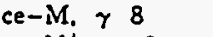 & 1.32E-02 & $4.732 E-02 *$ & $6.25 E-04$ \\
\hline $\mathrm{ce}-\mathrm{N}^{+}$, y 8 & $4.93 E-03$ & $5.162 \mathrm{E}-02^{-}$ & $2.54 E-04$ \\
\hline$c e-L_{31}$; 13 & $1.93 E-04$ & 4.778E-02 & $9.21 E-06$ \\
\hline$c e-L_{3}, \quad \gamma \quad 13$ & $1.48 \mathrm{E}-04$ & $5.156 \mathrm{E}-02$ & $7.65 E-06$ \\
\hline$\gamma 20$ & $1.30 E-05$ & $9.881 E-02$ & $1.28 E-06$ \\
\hline$\gamma 30$ & $6.20 \mathrm{E}-05$ & $1.293 E-01$ & $8.02 E-06$ \\
\hline$\gamma 47$ & $5.60 \mathrm{E}-06$ & $2.035 E-01$ & $1.14 \mathrm{E}-06$ \\
\hline$\gamma 69$ & $5.05 E-06$ & $3.328 \mathrm{E}-01$ & $1.68 E-06$ \\
\hline$\gamma 73$ & $5.61 \mathrm{E}-06$ & $3.450 \mathrm{E}-0 \mathrm{I}$ & $1.94 E-06$ \\
\hline$\gamma 78$ & $1.58 \mathrm{E}-05$ & $3.750 \mathrm{E}-01$ & $5.93 E-06$ \\
\hline Y 79 & $3.07 \mathrm{E}-06$ & 3.802E-01 & 1.17E-06 \\
\hline$\gamma 80$ & $2.60 \mathrm{E}-06$ & $3.827 \mathrm{E}-01$ & $9.95 E-07$ \\
\hline Y 81 & $2.60 \mathrm{E}-06$ & $3.827 \mathrm{E}-01$ & $9.95 \mathrm{E}-07$ \\
\hline Y 83 & $4.44 E-06$ & $3.931 \mathrm{E}-01$ & $1.75 E-06$ \\
\hline Y 87 & $1.51 E-05$ & $4.137 E-01$ & $6.25 \mathrm{E}-06$ \\
\hline$\gamma 93$ & $1.92 \mathrm{E}-06$ & $4.514 E-01$ & $8.67 E-07$ \\
\hline$K \alpha_{1} X-r a y$ & $3.91 E-05$ & $9.844 E-02$ & $3.85 E-06$ \\
\hline$K \alpha_{2} X-r a y$ & $2.42 \mathrm{E}-05$ & $9.466 \mathrm{E}-02$ & $2.29 E-06$ \\
\hline$K \beta_{1} X$-ray & $9.15 \mathrm{E}-06$ & $1.113 \mathrm{E}-01$ & $1.02 E-06$ \\
\hline La X-ray & $1.48 \mathrm{E}-02$ & $1.360 \mathrm{E}-02^{\bullet}$ & $2.01 E-04$ \\
\hline L; X-ray & $2.09 E-02$ & $1.706 \mathrm{E}-02^{\circ}$ & $3.56 E-04$ \\
\hline Ly X-ray & $4.86 E-03$ & $2.030 \mathrm{E}-02^{*}$ & $9.86 \mathrm{E}-05$ \\
\hline$L \eta X$-ray & $4.20 \mathrm{E}-04$ & $1.540 \mathrm{E}-02$ & $6.47 E-06$ \\
\hline Le X-ray & $7.30 E-04$ & 1.162E-02 & $8.48 E-06$ \\
\hline Auger-LMM & 1.97E-02 & $1.060 E-02^{\circ}$ & $2.09 E-04$ \\
\hline Auger-LMX & $1.37 \mathrm{E}-02$ & $1.416 \mathrm{E}-02^{\circ}$ & $1.94 E-04$ \\
\hline Auger-LXY & $2.31 E-03$ & $1.696 \mathrm{E}-02 *$ & $3.92 \mathrm{E}-05$ \\
\hline Auger-MXY & 2.15E-01 & $4.109 \mathrm{E}-03^{\prime \prime}$ & $8.85 E-0.4$ \\
\hline$\Delta \mathrm{E}$ & $1.05 E-01$ & $9.935 E-04 *$ & $1.04 E-04$ \\
\hline \multirow{8}{*}{\multicolumn{3}{|c|}{ 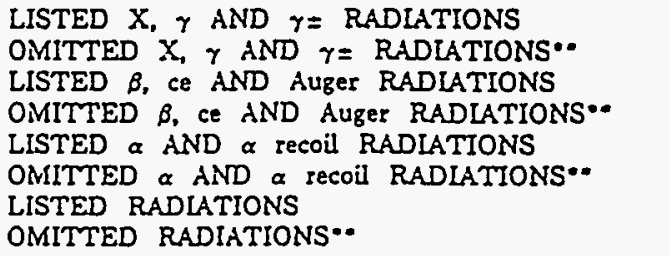 }} & $7.96 \mathrm{E}-04$ \\
\hline & & & $1.12 \mathrm{E}-05$ \\
\hline & & & $6.65 E-03$ \\
\hline & & & $8.75 E-05$ \\
\hline & & & $5.23 E \quad 00$ \\
\hline & & & $9.20 \mathrm{E}-03$ \\
\hline & & & $5.23 E \quad \infty$ \\
\hline & & & $9.30 E-03$ \\
\hline
\end{tabular}

- ayerage enERgy (MeV)

- each omitTEd transition contributes $<0.100 \%$ TO $\Sigma_{y}(\mathrm{i}) \times E(\mathrm{i})$ IN ITS CATEGORY. ITRANTM-235 DAUGHTER IS RADIOACTIVE. 


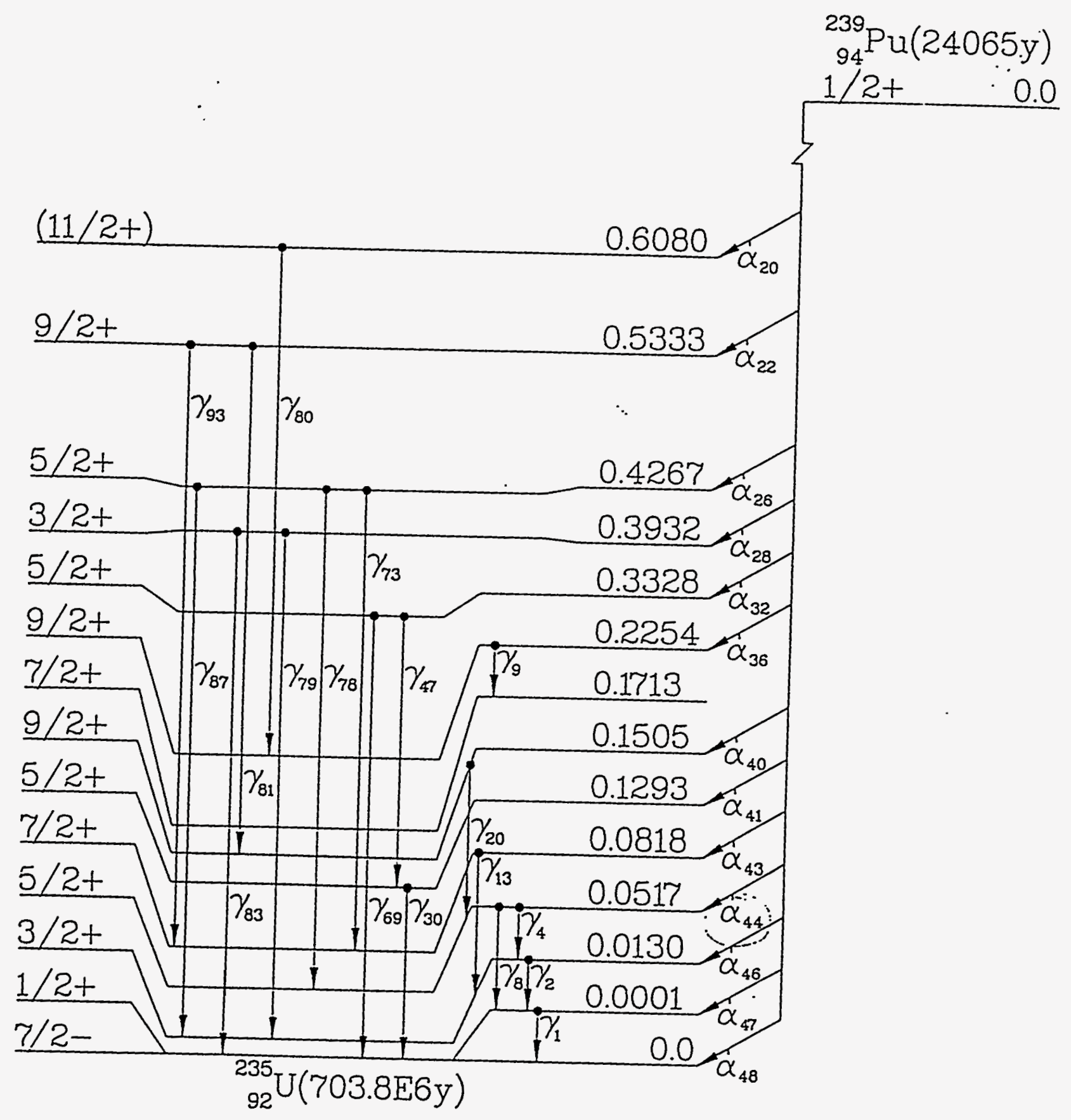


Appendix C

Statistics and Background Data 


\section{PERCENTAGE POINTS, CHI-SQUARE DISTRIBUTION}

This table gives values of $x^{2}$ such that

$$
F\left(x^{3}\right)=\int_{0}^{x^{2}} \frac{-1}{2^{\frac{\pi}{2}} \Gamma\left(\frac{n}{2}\right)} x^{\frac{x^{2}}{2}} e^{-\frac{1}{2} d x}
$$

for $n$, the number of degrees of treedom, equal to $1,2, \ldots, 30$. For $n>30$, s notmsl spproximstion is quite aceurste. The expression $\sqrt{2 x^{2}}-\sqrt{2 \pi-1}$ is spproximately normslly distributed as the atandard normal distribution. Thus $x^{3}$, the a-point of the distribution, msy be computed by the formula

$$
x^{2}=\frac{1}{f}\left[x_{\varepsilon}+\sqrt{2 n-1}\right]^{2},
$$

where $x_{*}$ is the a-point of the cumulative norms! diatribution. For even values of $n, F\left(x^{3}\right)$ can be wrillen so

$$
1-f\left(x^{2}\right)=\sum_{0=0}^{\infty-1} \frac{e^{-1} \lambda^{x}}{x !}
$$

with $\lambda=t x^{2}$ and $x^{\prime}-\downarrow n$. Tous the cumulative Cbi-Square distribution is related to the eumulstive Poisson distribution.

$$
\begin{aligned}
& \text { droxher epprosimale formula for large } n \\
& \qquad x^{3}-n\left(1-\frac{2}{9 n}+z_{-} \sqrt{\frac{2}{9 n}}\right)^{\prime}
\end{aligned}
$$

\begin{tabular}{|c|c|c|c|c|c|c|}
\hline$=$ & 1.232 & 1.645 & 1.960 & 2.326 & 2.:3is & 3.090 \\
\hline$F(x)$ & .90 & .93 & .973 & 99 & & .999 \\
\hline
\end{tabular}

$n$ - degrees of freediom

\begin{tabular}{|c|c|c|c|c|c|c|c|c|c|c|c|c|c|}
\hline 18 & .005 & .010 & .025 & .050 & .100 & .250 & .500 & .750 & .900 & .950 & .975 & .990 & .995 \\
\hline $\begin{array}{l}1 \\
2 \\
3 \\
4 \\
5\end{array}$ & $\begin{array}{l}.0000393 \\
.0100 \\
.0717 \\
.207 \\
.112\end{array}$ & $\begin{array}{l}.000157 \\
.0201 \\
.115 \\
.297 \\
.554\end{array}$ & $\begin{array}{l}.000982 \\
.0506 \\
.216 \\
.184 \\
.831\end{array}$ & $\begin{array}{l}.00393 \\
.103 \\
.352 \\
.711 \\
1.15\end{array}$ & $\begin{array}{l}.0158 \\
.211 \\
.584 \\
1.06 \\
1.61\end{array}$ & $\begin{array}{l}.102 \\
.375 \\
1.21 \\
1.92 \\
2.67\end{array}$ & $\begin{array}{l}.455 \\
1.39 \\
2.37 \\
3.35 \\
4.35\end{array}$ & $\begin{array}{l}1.32 \\
2.77 \\
4.11 \\
5.39 \\
6.63\end{array}$ & $\begin{array}{l}2.71 \\
t .61 \\
6.25 \\
7.78 \\
9.24\end{array}$ & $\begin{array}{c}3.81 \\
5.99 \\
7.81 \\
9.49 \\
11.1\end{array}$ & $\begin{array}{c}5.02 \\
7.38 \\
9.35 \\
11.1 \\
12.8\end{array}$ & $\begin{array}{r}8.63 \\
9.21 \\
11.3 \\
13.3 \\
1 . .1\end{array}$ & $\begin{array}{l}7.88 \\
10.6 \\
12.8 \\
11.9 \\
16.7\end{array}$ \\
\hline $\begin{array}{r}8 \\
7 \\
8 \\
9 \\
10\end{array}$ & $\begin{array}{l}.678 \\
.989 \\
1.34 \\
1.73 \\
2.16\end{array}$ & $\begin{array}{l}.872 \\
1.24 \\
1.65 \\
2.09 \\
2.38\end{array}$ & $\begin{array}{l}1.21 \\
1.69 \\
2.18 \\
2.70 \\
3.25\end{array}$ & $\begin{array}{l}1.61 \\
2.17 \\
2.73 \\
3.33 \\
3.91\end{array}$ & $\begin{array}{l}2.20 \\
2.83 \\
3.49 \\
4.17 \\
4.87\end{array}$ & $\begin{array}{l}3.45 \\
4.25 \\
5.07 \\
5.90 \\
6.74\end{array}$ & $\begin{array}{l}5.35 \\
8.35 \\
7.34 \\
8.34 \\
9.34\end{array}$ & $\begin{array}{c}7.34 \\
9.04 \\
10.2 \\
11.4 \\
12.5\end{array}$ & $\begin{array}{l}10.6 \\
12.0 \\
13.4 \\
14.7 \\
16.0\end{array}$ & $\begin{array}{l}12.6 \\
14.1 \\
15.5 \\
16.9 \\
18.3\end{array}$ & $\begin{array}{l}14.1 \\
16.0 \\
17.5 \\
190 \\
20.5\end{array}$ & $\begin{array}{l}16.8 \\
18.5 \\
20.1 \\
21.7 \\
23.2\end{array}$ & $\begin{array}{l}18.5 \\
20.3 \\
22.0 \\
23.6 \\
25.2\end{array}$ \\
\hline $\begin{array}{l}11 \\
12 \\
13 \\
14 \\
\text { is }\end{array}$ & $\begin{array}{l}2.60 \\
3.07 \\
3.57 \\
4.07 \\
4.60\end{array}$ & $\begin{array}{l}3.05 \\
3.57 \\
1.11 \\
1.86 \\
5.23\end{array}$ & $\begin{array}{l}3.82 \\
+.40 \\
3.01 \\
5.63 \\
6.26\end{array}$ & $\begin{array}{l}1.57 \\
3.23 \\
3.59 \\
6.57 \\
7.26\end{array}$ & $\begin{array}{l}5.58 \\
6.30 \\
7.04 \\
7.79 \\
8.55\end{array}$ & $\begin{array}{c}7.58 \\
8.41 \\
9.30 \\
10.2 \\
11.0\end{array}$ & $\begin{array}{l}10.3 \\
11.3 \\
12.3 \\
13.3 \\
.4 .3\end{array}$ & $\begin{array}{l}13.7 \\
14.8 \\
16.0 \\
17.1 \\
18.2\end{array}$ & $\begin{array}{l}17.3 \\
18.5 \\
19.8 \\
21.1 \\
22.3\end{array}$ & $\begin{array}{l}19.7 \\
21.0 \\
22.1 \\
23.7 \\
25.0\end{array}$ & $\begin{array}{l}21.9 \\
23.3 \\
24.7 \\
26.1 \\
27.5\end{array}$ & $\begin{array}{l}24.7 \\
26.2 \\
37.5 \\
29.1 \\
30.6\end{array}$ & $\begin{array}{l}26.8 \\
23.3 \\
29.3 \\
31.3 \\
32.9\end{array}$ \\
\hline $\begin{array}{l}16 \\
17 \\
18 \\
19 \\
20\end{array}$ & $\begin{array}{l}5.14 \\
5.70 \\
6.28 \\
6.94 \\
7.43\end{array}$ & $\begin{array}{l}5.81 \\
8.41 \\
7.01 \\
7.63 \\
8.26\end{array}$ & $\begin{array}{l}6.91 \\
7.36 \\
8.23 \\
3.91 \\
9.99\end{array}$ & $\begin{array}{c}7.96 \\
3.67 \\
9.39 \\
10.1 \\
10.9\end{array}$ & $\begin{array}{c}9.31 \\
10.1 \\
10.9 \\
11.7 \\
12.4\end{array}$ & $\begin{array}{l}11.9 \\
12.3 \\
13.7 \\
14.6 \\
15.3\end{array}$ & $\begin{array}{l}15.3 \\
16.3 \\
17.3 \\
18.3 \\
19.3\end{array}$ & $\begin{array}{l}19.4 \\
20.5 \\
21.6 \\
22.7 \\
23.8\end{array}$ & $\begin{array}{l}23.5 \\
24.8 \\
28.0 \\
27.2 \\
28.4\end{array}$ & $\begin{array}{l}26.3 \\
27.6 \\
23.9 \\
30.1 \\
31.4\end{array}$ & $\begin{array}{l}28.8 \\
30.2 \\
31.5 \\
32.9 \\
34.2\end{array}$ & $\begin{array}{l}32.0 \\
33.4 \\
34.3 \\
36.2 \\
376\end{array}$ & $\begin{array}{l}34.3 \\
35.7 \\
37.2 \\
35.6 \\
40.0\end{array}$ \\
\hline $\begin{array}{l}21 \\
22 \\
23 \\
23 \\
25\end{array}$ & $\begin{array}{c}8.03 \\
8.64 \\
9.26 \\
9.89 \\
10.5\end{array}$ & $\begin{array}{r}8.90 \\
9.51 \\
10.2 \\
10.9 \\
11.5\end{array}$ & $\begin{array}{l}10.3 \\
11.0 \\
11.7 \\
12.1 \\
13.1\end{array}$ & $\begin{array}{l}11.6 \\
12.3 \\
13.1 \\
13.8 \\
14.6\end{array}$ & $\begin{array}{l}13.2 \\
14.0 \\
14.8 \\
15.7 \\
16.5\end{array}$ & $\begin{array}{l}16.3 \\
17.2 \\
18.1 \\
19.0 \\
19.9\end{array}$ & $\begin{array}{l}20.3 \\
21.3 \\
22.3 \\
23.3 \\
24.3\end{array}$ & $\begin{array}{l}24.9 \\
26.0 \\
27.1 \\
23.2 \\
20.3\end{array}$ & $\begin{array}{l}29.6 \\
30.8 \\
32.0 \\
33.2 \\
34.1\end{array}$ & $\begin{array}{l}32.7 \\
33.9 \\
35.2 \\
36.4 \\
37.7\end{array}$ & $\begin{array}{l}35.5 \\
36.5 \\
38.1 \\
39.4 \\
10.6\end{array}$ & $\begin{array}{r}33.9 \\
10.3 \\
11.8 \\
+3.0 \\
14.3\end{array}$ & $\begin{array}{l}11.4 \\
\$ 2.8 \\
t+.2 \\
+1.8 \\
+6.9\end{array}$ \\
\hline $\begin{array}{l}28 \\
27 \\
23 \\
29 \\
30\end{array}$ & $\begin{array}{l}11.2 \\
11.8 \\
12.5 \\
13.1 \\
13.8\end{array}$ & $\begin{array}{l}12.2 \\
12.9 \\
13.6 \\
11.3 \\
15.0\end{array}$ & $\begin{array}{l}13.8 \\
14.6 \\
13.3 \\
16.0 \\
16.3\end{array}$ & \begin{tabular}{|l|}
15.1 \\
16.2 \\
16.9 \\
17.7 \\
18.5
\end{tabular} & $\begin{array}{l}17.3 \\
13.1 \\
18.9 \\
19.8 \\
20.8\end{array}$ & $\begin{array}{l}20.8 \\
21.7 \\
22.7 \\
23.6 \\
24.5\end{array}$ & $\begin{array}{l}25.3 \\
28.3 \\
27.3 \\
28.3 \\
29.3\end{array}$ & $\begin{array}{l}30.4 \\
31.5 \\
32.6 \\
33.7 \\
34.8\end{array}$ & $\begin{array}{l}35.6 \\
38.7 \\
37.9 \\
39.1 \\
40.3\end{array}$ & $\begin{array}{l}38.9 \\
10.1 \\
11.3 \\
12.6 \\
13.3\end{array}$ & $\begin{array}{l}+1.9 \\
13.2 \\
14.5 \\
15.7 \\
17.0\end{array}$ & $\begin{array}{l}456 \\
470 \\
4 \times .3 \\
49.6 \\
50.9\end{array}$ & $\begin{array}{l}43.3 \\
+9.6 \\
51.0 \\
33.3 \\
35.7\end{array}$ \\
\hline
\end{tabular}

2. - the normal deviate, (the value of $x$ for wbich $F(z)$ - the deaired pereentile). Ireedom.

$$
F\left(x^{2}\right)=\int_{0}^{x^{1}} \frac{1}{2^{\frac{1}{2}} r\left(\frac{n}{2}\right)} x^{\frac{n-2}{2}-e^{-\frac{3}{2}}} d x
$$


Statistics and Background Data

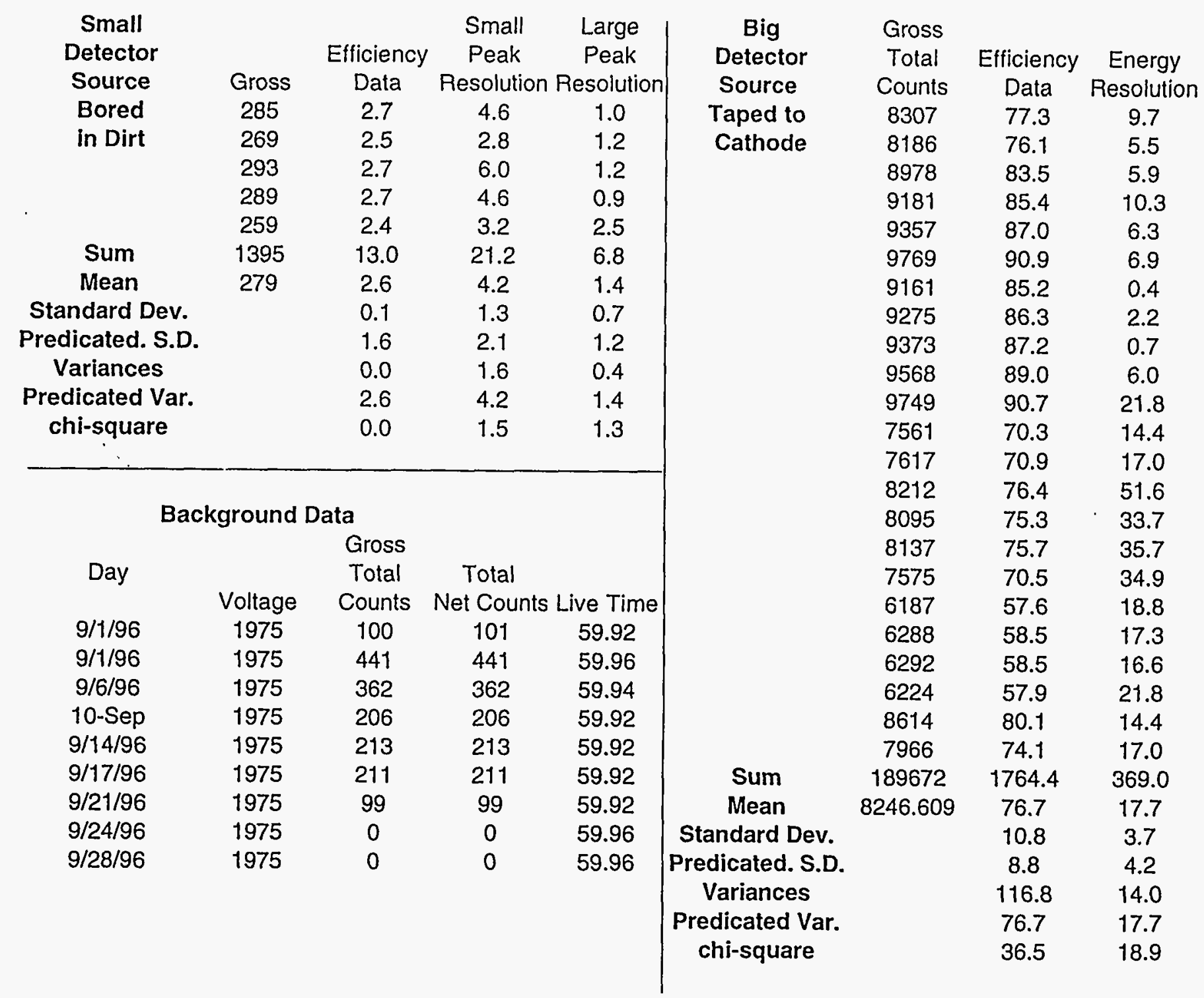


Appendix D

Counting Curve Data 


\begin{tabular}{|c|c|c|c|c|c|c|c|c|c|c|c|c|c|c|c|c|}
\hline & $\begin{array}{l}\text { Gross } \\
\text { Total }\end{array}$ & $\begin{array}{l}\text { Gross } \\
\text { Small }\end{array}$ & $\begin{array}{l}\text { Gross } \\
\text { Large }\end{array}$ & $\begin{array}{l}\text { Total } \\
\text { Net }\end{array}$ & $\begin{array}{l}\text { Total } \\
\text { Large }\end{array}$ & & $\begin{array}{l}\text { Total } \\
\text { Small }\end{array}$ & & $\begin{array}{l}\text { Small } \\
\text { Peak }\end{array}$ & $\begin{array}{c}\text { Small } \\
\text { Centroid }\end{array}$ & $\begin{array}{l}\text { Big } \\
\text { Peak }\end{array}$ & $\begin{array}{c}\text { Big } \\
\text { Centroid }\end{array}$ & & $\begin{array}{l}\text { Absolute } \\
\text { Elficiency }\end{array}$ & $\begin{array}{l}\text { Absolute } \\
\text { Efficiency }\end{array}$ & Resolution \\
\hline Voltage & Counts & Peak & Peak & Counts & Peak & + & Peak & + & FWHM & Peak & FWHM & Peak & Live Time & Full Counis & $.1 \mathrm{MeV}$ Peak & \\
\hline 1400 & 1 & 1 & 1 & 1 & 1 & 1 & 1 & 0 & 0 & 0 & 0 & 0 & 59.96 & $9.3 E-3$ & $9.3 E-3$ & \\
\hline 1450 & 2 & 1 & 1 & 2 & 1 & 2 & 1 & 0 & 0 & 0 & 0 & 0 & 59.96 & $18.6 E-3$ & $9.3 E-3$ & \\
\hline 1500 & 1 & 1 & 1 & 1 & 1 & 0 & 1 & 0 & 0 & 0 & 0 & 0 & 59.78 & $9.3 E-3$ & $9.3 E-3$ & \\
\hline 1525 & 54 & 1 & 1 & 52 & 1 & 10 & 1 & 0 & 0 & 0 & 0 & 0 & 59.72 & 502.3E-3 & $9.3 E-3$ & \\
\hline 1550 & 104 & 1 & 1 & 102 & 1 & 12 & 1 & 0 & 0 & 0 & 0 & 0 & 59.68 & $967.4 \mathrm{E}-3$ & $9.3 \mathrm{E}-3$ & \\
\hline 1575 & 197 & 1 & 1 & 194 & 1 & 17 & 1 & 0 & 0 & 0 & 0 & 0 & 59.68 & $1.8 \mathrm{E}+0$ & $9.3 E-3$ & \\
\hline 1600 & 357 & 184 & 1 & 302 & 1 & 46 & 82 & 27 & 6 & 0 & 0 & 0 & 59.56 & $3.3 E+0$ & $9.3 E-3$ & \\
\hline 1625 & 545 & 242 & 1 & 542 & 1 & 25 & 164 & 21 & 3 & 0 & 0 & 0 & 59.5 & $5.1 E+0$ & $9.3 E-3$ & \\
\hline 1675 & 1339 & 504 & 640 & 1287 & 312 & 54 & 342 & 31 & 9 & 116 & 2 & 188 & 59.44 & $12.5 E+0$ & $6.0 E+0$ & 8.2 \\
\hline 1700 & 1998 & 656 & 1140 & 1898 & 568 & 70 & 403 & 38 & 13 & 115 & 21 & 193 & 59.36 & $18.6 E+0$ & $10.6 E+0$ & 11.6 \\
\hline 1725 & 2802 & 606 & 2000 & 2800 & 1374 & 53 & 417 & 35 & 12 & 116 & 17 & 200 & 59.28 & $26.1 E+0$ & $18.6 E+0$ & 10.1 \\
\hline 1750 & 2490 & 706 & 1531 & 2486 & 1079 & 51 & 480 & 37 & 13 & 115 & 18 & 197 & 59.32 & $23.2 \mathrm{E}+0$ & $14.2 E+0$ & 11.7 \\
\hline 1775 & 3314 & 514 & 2554 & 3219 & 2090 & 74 & 332 & 31 & 17 & 116 & 26 & 199 & 59.22 & $30.8 E+0$ & $23.8 E+O$ & 14.9 \\
\hline 1800 & 3723 & 418 & 3087 & 3641 & 2638 & 75 & 261 & 29 & 9 & 117 & 16 & 199 & 59.16 & $34.6 E+0$ & $28.7 E+0$ & 7.4 \\
\hline 1825 & 4083 & 366 & 3556 & 3915 & 3285 & 91 & 239 & 27 & 16 & 119 & 20 & 199 & 59.1 & $38.0 E+0$ & $33.1 E+0$ & 13.6 \\
\hline 1850 & 4608 & 424 & 4156 & 4326 & 3994 & 107 & 295 & 36 & 7 & 116 & 16 & 200 & 59 & $42.9 E+0$ & $38.7 E+0$ & 5.7 \\
\hline 1875 & 4673 & 436 & 4221 & 4459 & 3915 & 99 & 204 & 45 & 2 & 120 & 17 & 202 & 58.98 & $43.5 E+0$ & $39.3 E+0$ & 1.5 \\
\hline 1900 & 5147 & 428 & 4714 & 5010 & 4377 & 92 & 279 & 38 & 16 & 118 & 17 & 202 & 58.9 & $47.9 E+0$ & $43.9 E+0$ & 13.6 \\
\hline 1950 & 5735 & 399 & 5186 & 5647 & 4906 & 89 & 193 & 35 & 9 & 116 & 25 & 205 & 58.74 & $53.3 E+0$ & $48.2 E+0$ & 7.4 \\
\hline 1975 & 6003 & 376 & 5452 & 5570 & 5005 & 130 & 132 & 30 & 6 & 116 & 19 & 208 & 58.64 & $55.8 E+0$ & $50.7 E+0$ & 5.6 \\
\hline 2000 & 6118 & 447 & 5687 & 5439 & 5080 & 145 & 223 & 35 & 5 & 118 & 28 & 206 & 58.46 & $56.9 E+0$ & $52.9 E+0$ & 3.8 \\
\hline & $\begin{array}{l}\text { Gross } \\
\text { Total }\end{array}$ & $\begin{array}{c}\text { Big } \\
\text { Gross }\end{array}$ & $\begin{array}{l}\text { Small } \\
\text { Gross }\end{array}$ & $\begin{array}{c}\text { Total } \\
\mathrm{Net}\end{array}$ & $\begin{array}{l}\mathrm{Big} \\
\mathrm{Net}\end{array}$ & $\begin{array}{c}\text { Small } \\
\text { Net }\end{array}$ & Big & Big & Small & Small & & $\begin{array}{l}\text { Absolute } \\
\text { Elficiency }\end{array}$ & $\begin{array}{l}\text { Absolute } \\
\text { Efficiency }\end{array}$ & $\begin{array}{c}\text { Big } \\
\text { Resolution }\end{array}$ & $\begin{array}{c}\text { Small } \\
\text { Resolution }\end{array}$ & \\
\hline Voltage & Counts & peak & Peak & Counts & Counts & Counts & FWHM & Peak & FWHM & Peak & Live Time & Full Counts & Big Peak & . & & \\
\hline 1600 & 1 & 1 & 1 & 0 & 0 & 0 & $\mathrm{n} / \mathrm{a}$ & $\mathrm{n} / \mathbf{a}$ & $\mathrm{n} / \mathrm{a}$ & $\mathrm{n} / \mathrm{a}$ & 59.98 & $9.3 \mathrm{E}-3$ & $9.3 \mathrm{E}-3$ & & & \\
\hline 1700 & 47 & 1 & 1 & 45 & 0 & 0 & $\mathrm{n} / \mathrm{a}$ & na & $\mathrm{n} / \mathrm{a}$ & $\mathrm{Na}$ & 59.96 & 437.2E-3 & $9.3 E-3$ & & & \\
\hline 1800 & 247 & 163 & 76 & 246 & 159 & 74 & 6.3 & 193.5 & 2 & 116 & 59.92 & $2.3 E+0$ & $1.5 \mathrm{E}+0$ & 1.3 & 3.3 & \\
\hline 1900 & 285 & 210 & 75 & 282 & 206 & 73 & 9.9 & 213.6 & 1 & 128 & 59.92 & $2.7 E+0$ & $2.0 E+0$ & 1.0 & 4.6 & \\
\hline
\end{tabular}


Counting Curve Data for Large Detector with Source Taped to Detector

\begin{tabular}{|c|c|c|c|c|c|c|c|c|c|c|c|c|c|c|}
\hline Voltage & $\begin{array}{l}\text { Gross } \\
\text { Total } \\
\text { Counts }\end{array}$ & $\begin{array}{l}\text { Gross } \\
\text { Small } \\
\text { Counts }\end{array}$ & $\begin{array}{l}\text { Gross } \\
\text { Large } \\
\text { Counts }\end{array}$ & $\begin{array}{c}\text { Net } \\
\text { Total } \\
\text { Counts }\end{array}$ & $\begin{array}{c}\text { Net } \\
\text { Small } \\
\text { Counts }\end{array}$ & $\begin{array}{c}\text { Net } \\
\text { Large } \\
\text { Counts }\end{array}$ & $\begin{array}{l}\text { Small } \\
\text { FWHM }\end{array}$ & $\begin{array}{l}\text { Centroid } \\
\text { Peak } \\
\text { Channle }\end{array}$ & $\begin{array}{c}\text { Big } \\
\text { FWHM }\end{array}$ & $\begin{array}{l}\text { Centroid } \\
\text { Peak } \\
\text { Peak }\end{array}$ & Live Time & $\begin{array}{l}\text { Absolute } \\
\text { Efficiency } \\
\text { Full Counts }\end{array}$ & $\begin{array}{c}\text { Small } \\
\text { Resolution }\end{array}$ & $\begin{array}{c}\text { Big } \\
\text { Resolution }\end{array}$ \\
\hline 750 & 1 & 1 & 1 & 1 & 1 & 1 & n/a & $\mathrm{n} / \mathrm{a}$ & $n / a$ & $\mathrm{n} / \mathrm{a}$ & 59.84 & 0.0 & & \\
\hline 800 & 2 & 2 & 1 & 2 & 2 & 1 & $\mathrm{Na}$ & $\mathrm{Na}$ & $\mathrm{n} / \mathrm{a}$ & na & 59.84 & 0.0 & & \\
\hline 850 & 2 & 2 & 1 & 2 & 2 & 1 & $\mathrm{n} / \mathrm{a}$ & $\mathrm{n} / \mathrm{a}$ & $\mathrm{n} / \mathrm{a}$ & na & 59.84 & 0.0 & & \\
\hline 900 & 34 & 34 & 1 & 33 & 33 & 1 & $\mathrm{n} / \mathrm{a}$ & Na & 4.0 & 246 & 59.84 & 0.3 & & \\
\hline 950 & 55 & 55 & 1 & 52 & 52 & 1 & $\mathrm{n} / \mathrm{a}$ & $\mathrm{na}$ & 5.4 & 242 & 59.84 & 0.5 & & \\
\hline 1000 & 96 & 96 & 1 & 96 & 96 & 1 & $\mathrm{~N} / \mathrm{a}$ & $\mathrm{n} / \mathrm{a}$ & 4.5 & 240 & 59.2 & 0.9 & & \\
\hline 1050 & 270 & 270 & 1 & 266 & 266 & 1 & $\mathrm{n} / \mathrm{a}$ & $\mathrm{n} / \mathrm{a}$ & 4.2 & 236 & 59.74 & 2.5 & & \\
\hline 1100 & 219 & 219 & 1 & 202 & 202 & 1 & $\mathrm{n} / \mathrm{a}$ & $\mathrm{n} / \mathrm{a}$ & 4.0 & 236 & 59.76 & 2.0 & & \\
\hline 1150 & 271 & 271 & 1 & 270 & 270 & 1 & $\mathrm{Na}$ & $\mathrm{n} / \mathrm{a}$ & 4.2 & 236 & 59.72 & 2.5 & & \\
\hline 1200 & 485 & 485 & 1 & 482 & 485 & 1 & $\mathrm{n} / \mathrm{a}$ & $\mathrm{N} / \mathrm{a}$ & 4.7 & 236 & 59.72 & 4.5 & & \\
\hline 1250 & 856 & 856 & 1 & 852 & 852 & 1 & $\mathrm{n} / \mathrm{a}$ & $\mathrm{n} / \mathrm{a}$ & 4.5 & 235 & 59.72 & 8.0 & & \\
\hline 1300 & 1251 & 1251 & 1 & 1218 & 1218 & 1 & $\mathrm{Na}$ & $\mathrm{N} / \mathrm{a}$ & 6.0 & 234 & 59.72 & 11.6 & & \\
\hline 1350 & 1282 & 1282 & 1 & 1280 & 1280 & 1 & $\mathrm{~N} / \mathrm{a}$ & Na & 19.9 & 255 & 59.32 & 11.9 & & \\
\hline 1400 & 1669 & 1669 & 1 & 1666 & 1666 & 1 & $\mathrm{Na}$ & $\mathrm{Na}$ & 20.8 & 251 & 59.14 & 15.5 & & \\
\hline 1450 & 1959 & 1908 & 1 & 1640 & 1845 & 1 & $\mathrm{n} / \mathrm{a}$ & $\mathrm{n} / \mathrm{a}$ & 8.1 & 247 & 58.96 & 18.2 & & \\
\hline 1500 & 2053 & 1996 & 1 & 2047 & 1927 & 1 & Na & $\mathrm{n} / \mathrm{a}$ & 7.1 & 247 & 59.14 & 19.1 & & \\
\hline 1600 & 2655 & 2257 & 298 & 2065 & 2090 & 202 & 14.7 & 183 & 7.2 & 247 & 58.8 & 24.7 & 8.1 & 3.9 \\
\hline 1650 & 5722 & 2336 & 3353 & 4374 & 2360 & 193 & 21.7 & 172 & 7.3 & 248 & 58.68 & 53.2 & 12.6 & 4.3 \\
\hline 1700 & 7268 & 2311 & 3938 & 6722 & 2677 & 132 & 12.8 & 198 & 7.7 & 248 & 58.64 & 67.6 & 6.5 & 3.9 \\
\hline 1750 & 7731 & 1951 & 5090 & 7052 & 4146 & 223 & 10.5 & 206 & 9.1 & 250 & 58.62 & 71.9 & 5.1 & 4.4 \\
\hline 1800 & 8298 & 1922 & 5826 & 7805 & 4947 & 223 & 12.5 & 210 & 8.9 & 248 & 58.54 & 77.2 & 6.0 & 4.2 \\
\hline 1850 & 8600 & 1972 & 6356 & 8267 & 5219 & 223 & 13.6 & 214 & 11.0 & 248 & 58.48 & 80.0 & 6.3 & 5.1 \\
\hline 1900 & 9129 & 2316 & 6515 & 8699 & 5002 & 223 & 13.4 & 216 & 9.6 & 251 & 58.4 & 84.9 & 6.2 & 4.4 \\
\hline 1950 & 9043 & 2302 & 6434 & 8299 & 4121 & 223 & 18.5 & 219 & 11.3 & 252 & 58.34 & 84.1 & 8.5 & 5.2 \\
\hline 2000 & 9370 & & & & & & & & & & 58.34 & 87.2 & & \\
\hline
\end{tabular}


Appendix E

Efficiency and Energy Resolution Data 
Efficieny and Energy Resolution

\begin{tabular}{|c|c|c|c|c|c|c|c|c|c|c|c|c|}
\hline $\begin{array}{c}\text { Small } \\
\text { Detector } \\
\text { Source }\end{array}$ & Voltage & $\begin{array}{l}\text { Gross } \\
\text { Total } \\
\text { Counts }\end{array}$ & $\begin{array}{l}\text { Big } \\
\text { Gross } \\
\text { peak }\end{array}$ & $\begin{array}{l}\text { Big } \\
\text { FWHM }\end{array}$ & $\begin{array}{l}\text { Big } \\
\text { Peak }\end{array}$ & $\begin{array}{l}\text { Small } \\
\text { FWHM }\end{array}$ & $\begin{array}{l}\text { Small } \\
\text { Peak }\end{array}$ & Live Time & $\begin{array}{l}\text { Absolute } \\
\text { Efficiency } \\
\text { Full Counts }\end{array}$ & $\begin{array}{l}\text { Absolute } \\
\text { Efficiency } \\
\text { Big Peak }\end{array}$ & $\begin{array}{c}\text { Big } \\
\text { Resolution }\end{array}$ & $\begin{array}{c}\text { Small } \\
\text { Resolution }\end{array}$ \\
\hline Bored & 1900 & 285 & 210 & 9.9 & 214 & 1.3 & 128 & 59.92 & 2.7 & 2.0 & 1.0 & 4.6 \\
\hline in & 1900 & 269 & 178 & 5.9 & 215 & 1.2 & 102 & 59.96 & 2.5 & 1.7 & 1.2 & 2.8 \\
\hline \multirow[t]{3}{*}{ Dirt } & 1900 & 293 & 197 & 12.0 & 202 & 1.5 & 117 & 59.96 & 2.7 & 1.8 & 1.2 & 6.0 \\
\hline & 1900 & 289 & 200 & 9.9 & 215 & 1.1 & 124 & 59.92 & 2.7 & 1.9 & 0.9 & 4.6 \\
\hline & 1900 & 259 & 199 & 6.4 & 201 & 2.6 & 104 & 59.94 & 2.4 & 1.9 & 2.5 & 3.2 \\
\hline \multirow{15}{*}{$\begin{array}{c}\text { Big } \\
\text { Detector } \\
\text { Week of } \\
\text { 1-Sep-96 }\end{array}$} & & & & & & & & & & & & \\
\hline & & Gross & Net & & Small & & Big. & & Absolute & Absolute & Big & Smail \\
\hline & & Total & Total & Small & Centroid & Big & Centroid & & Efficiency & Efficiency & Peak & Peak \\
\hline & Voltage & Counts & Counts & FWHM & Peak & FWHM & Peak & Live Time & Full Counts & Big Peak & Resolution & Resolution \\
\hline & 1975 & 8307 & 6445 & 28.1 & 291 & 19.8 & 217 & 58.28 & 77.3 & 60.0 & 9.1 & 9.7 \\
\hline & 1975 & 8186 & 6277 & 14.7 & 266 & 15.1 & 215 & 58.48 & 76.1 & 58.4 & 7.1 & 5.5 \\
\hline & 1975 & 8978 & 6387 & 15.4 & 260 & 13.0 & 215 & 58.3 & 83.5 & 59.4 & 6.0 & 5.9 \\
\hline & 1975 & 9181 & 6516 & 27.5 & 268 & 17.3 & 216 & 58.12 & 85.4 & 60.6 & 8.0 & 10.3 \\
\hline & 1975 & 9357 & 6304 & 16.3 & 259 & 14.7 & 216 & 58.16 & 87.0 & 58.6 & 6.8 & 6.3 \\
\hline & 1975 & 9769 . & 6216 & 17.9 & 260 & 16.3 & 217 & 57.92 & 90.9 & 57.8. & 7.5 & 6.9 \\
\hline & 1975 & 9161 & 6493 & 1.0 & 255 & 16.6 & 218 & 58.04 & 85.2 & 60.4 & 7.6 & 0.4 \\
\hline & 1975 & 9275 & 6459 & 5.6 & 253 & 18.0 & 217 & 58 & 86.3 & 60.1 & 8.3 & 2.2 \\
\hline & 1975 & 9373 & 6377 & 1.7 & 254 & 16.2 & 218 & 58 & 87.2 & 59.3 & 7.4 & 0.7 \\
\hline & 1975 & 9568 & 6413 & 15.1 & 250 & 18.1 & 219 & 58.02 & 89.0 & 59.7 & 8.3 & 6.0 \\
\hline & & & & only peak & only peak & & & & & & & Only Peak \\
\hline \multirow[t]{3}{*}{ 9/8/96 } & 1975 & 9749 & & 56.6 & 260 & & & 56.46 & 90.7 & & & 21.8 \\
\hline & 1975 & 7561 & & 35.6 & 247 & & & 57.34 & 70.3 & & & 14.4 \\
\hline & 1975 & 7617 & & 42.2 & 249 & & & 57.42 & 70.9 & & & 17.0 \\
\hline \multirow[t]{4}{*}{ 9/20/96 } & 1975 & 8212 & & 172.0 & 333 & & & 58.4 & 76.4 & & & 51.6 \\
\hline & 1975 & 8095 & & 103.8 & 309 & & & 57.94 & 75.3 & & & 33.7 \\
\hline & 1975 & 8137 & & 99.8 & 279 & & & 58.2 & 75.7 & & & 35.7 \\
\hline & 1975 & 7575 & & 99.8 & 286 & & & 57.8 & 70.5 & & & 34.9 \\
\hline \multirow[t]{6}{*}{$9 / 22 / 96$} & 1975 & 6187 & 5697 & 7.0 & 294 & 33.4 & 178 & 58.94 & 57.6 & 53.0 & 18.8 & 2.4 \\
\hline & 1975 & 6288 & 5827 & 9.2 & 301 & 32.2 & 186 & 58.94 & 58.5 & 54.2 & 17.3 & 3.0 \\
\hline & 1975 & 6292 & 5824 & 4.1 & 306 & 32.1 & 193 & 58.96 & 58.5 & 54.2 & 16.6 & 1.3 \\
\hline & 1975 & 6224 & 5684 & 2.0 & 310 & 32.0 & 199 & 58.78 & 57.9 & 52.9 & 16.1 & 0.6 \\
\hline & 1975 & 8614 & & & & & & & 80.1 & & & \\
\hline & 1975 & 7966 & & & & & & & 74.1 & & & \\
\hline
\end{tabular}


Appendix F

Semiconductor Data 


\begin{tabular}{|c|c|c|c|c|c|c|c|c|c|}
\hline \multirow{3}{*}{$\begin{array}{c}\text { Pressure } \\
0 \mathrm{~mm}\end{array}$} & \multicolumn{9}{|c|}{ Centroid } \\
\hline & Data & Gross & Net & & Peak & & & & \\
\hline & Number & Counts & Counts & plus/minus & Channel & FWHM & Live Time & Efficien & esolution \\
\hline & 1 & 1035 & 1035 & 32 & .209 & 15.6 & 59.58 & 9.6 & 7.5 \\
\hline & 2 & 1023 & 1022 & 32 & 219 & 27.2 & 59.56 & 9.5 & 12.4 \\
\hline & 3 & 1014 & 1014 & 31 & 211 & 22.9 & 59.58 & 9.4 & 10.8 \\
\hline & 4 & 1042 & 1040 & 33 & 207 & 31.7 & 59.56 & 9.7 & 15.3 \\
\hline & 5 & 1003 & 1002 & 32 & 223 & 30.7 & 59.58 & 9.3 & 13.8 \\
\hline & 6 & 968 & 968 & 31 & 214 & 30.0 & 59.56 & 9.0 & 14.0 \\
\hline & 7 & 984 & 983 & 31 & 198 & 34.4 & 59.58 & 9.2 & 17.3 \\
\hline & 8 & 1033 & 1033 & 32 & 213 & 16.5 & 59.56 & 9.6 & 7.7 \\
\hline & 9 & 1070 & 1022 & 49 & 211 & 19.6 & 59.58 & 10.0 & 9.3 \\
\hline & 10 & 955 & 954 & 31 & 210 & 28.8 & 59.56 & 8.9 & 13.7 \\
\hline & & & & & & & Mean & 9.4 & 12.2 \\
\hline & & & & & & & Var & 0.1 & 10.7 \\
\hline & & & & & & & S.D & 0.3 & 3.3 \\
\hline
\end{tabular}

$30 \mathrm{~mm}$

\begin{tabular}{|c|c|c|c|c|c|c|c|c|}
\hline 1 & 967 & 966 & 31 & 369 & 18.4 & 59.56 & 9.0 & 5.0 \\
\hline 2 & 947 & 947 & 30 & 369 & 21.4 & 59.58 & 8.8 & 5.8 \\
\hline 3 & 949 & 949 & 30 & 370 & 18.4 & 59.56 & 8.8 & 5.0 \\
\hline 4 & 976 & 975 & 31 & 368 & 17.0 & 58.58 & 9.1 & 4.6 \\
\hline 5 & 976 & 974 & 31 & 368 & 17.7 & 59.56 & 9.1 & 4.8 \\
\hline 6 & 997 & 994 & 32 & 369 & 18.3 & 59.58 & 9.3 & 5.0 \\
\hline 7 & 1028 & 1027 & 32 & 369 & 15.8 & 59.56 & 9.6 & 4.3 \\
\hline 8 & 960 & 959 & 31 & 369 & 13.8 & 59.58 & 8.9 & 3.7 \\
\hline 9 & 998 & 998 & 31 & 370 & 22.4 & 59.56 & 9.3 & 6.1 \\
\hline \multirow[t]{4}{*}{10} & 955 & 955 & 30 & 371 & 20.7 & 59.58 & 8.9 & 5.6 \\
\hline & & & & & & Mean & 9.1 & 5.0 \\
\hline & & & & & & Var & 0.1 & 0.5 \\
\hline & & & & & & S.D & 0.2 & 0.7 \\
\hline
\end{tabular}

$60 \mathrm{~mm}$

$\begin{array}{ccccccccc}1 & 1105 & 1104 & 33 & 270 & 16.2 & 59.56 & 10.3 & 5.0 \\ 2 & 1097 & 1097 & 33 & 270 & 17.9 & 59.58 & 10.2 & 6.6 \\ 3 & 1083 & 1082 & 33 & 269 & 21.2 & 59.56 & 10.1 & 7.9 \\ 4 & 1119 & 1118 & 33 & 370 & 16.5 & 59.58 & 10.4 & 4.5 \\ 5 & 1092 & 1090 & 33 & 369 & 12.5 & 59.56 & 10.2 & 3.4 \\ 6 & 1092 & 1088 & 33 & 370 & 20.0 & 59.58 & 10.2 & 5.4 \\ 7 & 1069 & 1011 & 40 & 369 & 13.8 & 59.56 & 9.9 & 3.7 \\ 8 & 1016 & 1013 & 32 & 370 & .20 .5 & 59.58 & 9.5 & 5.5 \\ 9 & 1094 & 1019 & 43 & 372 & 17.9 & 59.56 & 10.2 & 4.8 \\ 10 & 1095 & 1074 & 36 & 370 & 17.3 & 59.58 & 10.2 & 4.7 \\ & & & & & & \text { Mean } & 10.1 & 5.2 \\ & & & & & & \text { Var } & 0.1 & 1.8 \\ & & & & & & \text { S.D } & 0.3 & 1.3\end{array}$




\section{References}

Akande, Wole. A method of evaluation of gas gain proportional counters. Review of Scientific Instruments. 63 (10) October 1992

Aldrich, Catalog Handbook of Fine Chemicals 1994-1995

Annals of the ICRP, Radionuclide Transformations, Energy and Intensity of Emissions, ICRP Publication \#38, Volumes 11-13, 1983

Bambynek, W. On Selected Problems in the Field of Proportional Counters Nuclear Instruments and Methods 112(1973) 103-110

Campion, P.J. Spurious Pulses in Proportional Counters, A Review. Nuclear Instruments and Methods 112(1973) 75-81

Chao, J.H., Chung, C. Radionuclide Monitoring in Environmental Water Body Using an In Situ Gamma Probe, Applied Radiation Isotopes Vol. 43 . No.4 (1992) 475-480

Christophorou, L.G., McCorkle, D.L., Maxey, D.V., Carter, J.G. Fast Gas Mixtures For Gas-Filled particle Detector. Nuclear Instruments and Methods. 163(1979) 141-149

Closing the Circle on the Splitting of the Atom, U.S. Department of Energy Office of Environmental Management.

Currie, Lloyd A., Limits for Qualitative Detection and Quantitative Determination, Applications to Radiochemistry, Analytical Chemistry, Jan 1968.

External Exposure To Radionuclides In Air, Water, and Soil, Environmental Protection Agency Federal Guidance Report No. 12.

Fjeld, R.A., Montague, M.H., Haapala, M.H., Kotrappa, P. Field Test of Electret Ion Chambers for Environmental Monitoring, Health Physics Vol. 66 No. 2. (1994) 147-154

Kageyama, Losuke and Hayashibe, Shogo and Kanazaqa, Masaaki and Watanabe, Hiroshi and Fujioka Manabu. Characteristics of a single wire proportional counter with very thin rectangular cross section, Nuclear Instruments and methods in Physics Research A 342 1994 509-515

Genz, Harald. Single Electron Detection in Proportional Gas Counters Nuclear Instruments and Methods 112(1973) 83-90

Gillespie, A.B. Signal, Noise and Resolution in Nuclear Counter Amplifiers, London Pergamon Press, LTD, 1953. 


\section{References Cont}

Helfer, Irene K. and Miller, Kevin M. Calibration Factors for Ge Detectors Used for Field Spectrometry, Health Physics Vol. 55 No. 1 (July), pp. 15-29, 1988

Hendricks, R.W. The Gas Amplification Factor in Xenon Filled Proportional Counters. Nuclear Instruments and Methods. 102(1972) 309-312.

Horstman, H.M. Ventrua, G. Vespignani, G.R. Field Corrector for Proportional Counters Nuclear Instruments and Methods 112(1973) 619-320

Hsu, Pin-Chieh and Weng, Pao-Shan and Wang, Hsiang-En and Tseng, Po-Wen. Monitoring Underground Radiation Fields Using Powdered Calcium Sulfate

Thermoluminescent Dosimeters. Health Physics Vol. 61, No. 3 (September) pp. 367-371, 1991.

Kiser, R.W. Applied Scientific Research, Volume 8 page 183, 1960.

Kobrin, Paul H., Schick, G. Alan, Baxter, James P., and Nicholas Winograd, Detector for measuring energy- and angle-resolved neutral-particle (EARN) distributions for material desorbed from bombarded surfaces. Review of Scientific Instruments 57 (7), July 1986 pp. 1354-1362

Knoll, Glenn F. Radiation Detection and Measurements Third Edition

MacArthur, D.W. Allander, K.S. Bounds, J.A. Butterfield, K.B. and McAtee, J.L. Long-Range Alpha Detector. Health Physics Vol. 63, No.3 September 1992 pp. 324-330.

Mendenhall, Beaver, Introduction To Probability and Statistics, Ninth Edition 1994

Miller, Kevin M. Shebell, Peter and Klemic, Gladys A. In Situ Gamma-Ray Spectrometry for the Measurement of Uranium in Surface Soils, Health Physics, August 1994 Volume 67 , Number 2

Povinec, Pavel. A Study of Proportional Counter Optimization for Long-Term Counting. Nuclear Instruments and Methods. 163(1979) 363-368.

Radiological Health Handbook, U.S. Department of Health, Education and Welfare. Washington D.C. 1970

Schilk, A.J., Knoph, M.A., Thompson, R.C., Hubbard, C.W., Abel, K.H., Edwards, D.R. and Abraham, J.R. Real-time, in situ detection of Sr-90 and U-238 in soils via scintillating-fiber-sensor technology. Nuclear Instruments and Methods in Physics Research A 353 (1994) 477-481. 


\section{References Cont.}

Sipila, Heikki. Energy Resolution of the Proportional Counter. Nuclear Instruments and Methods. 133(1976) 251-252.

Wilkinson, D.H. Ionization Chambers and Counters, Cambridge Press 1950

Wolff, Richard S. Measurement of the Gas Constants for Various Proportional-Counter Gas Mixtures. Nuclear Instruments and Methods. 115(1974) 461-463. 